\title{
A Labor Capital Asset Pricing Model*
}

\author{
Lars-Alexander Kuehn \\ Tepper School of Business \\ Carnegie Mellon University
}

\author{
Mikhail Simutin \\ Rotman School of Management \\ University of Toronto
}

\author{
Jessie Jiaxu Wang \\ Tepper School of Business \\ Carnegie Mellon University
}

February 12, 2014

\begin{abstract}
We show that labor search frictions are an important determinant of the cross-section of equity returns. In the data, sorting firms by loadings on labor market tightness, the key statistic of search models, generates a spread in future returns of $6 \%$ annually. We propose a partial equilibrium labor market model in which heterogeneous firms make optimal employment decisions under labor search frictions. In the model, loadings on labor market tightness proxy for priced time variation in the efficiency of the matching technology. Firms with low loadings are not hedged against adverse matching efficiency shocks and require higher expected stock returns.
\end{abstract}

JEL Classification: E24, G12, J21

Keywords: Cross sectional asset pricing, labor search frictions, labor market tightness, labor market mismatch.

${ }^{*}$ We thank Frederico Belo, Ilan Cooper, Andres Donangelo, Vito Gala, Brent Glover, Burton Hollifield, Finn Kydland, Stefan Nagel, Stavros Panageas, Dimitris Papanikolaou, Nicolas Petrosky-Nadeau, Chris Telmer, Ping Yan, Lu Zhang; conference participants of the 2012 Western Economic Association Annual Conference, 2012 Midwest Macroeconomics Meeting, 2013 Midwest Finance Association Meeting, 2013 ASU Sonoran Winter Finance Conference, 2013 SFS Finance Cavalcade, 2013 CAPR Workshop on Production Based Asset Pricing at BI Norway, 2014 American Finance Association Meeting, and seminar participants at Carnegie Mellon University, Goethe Universität Frankfurt, ESMT, Humboldt Universität Berlin, University of Virginia (Darden), and University of Michigan for helpful comments. Contact information, Kuehn: 5000 Forbes Avenue, Pittsburgh, PA 15213, kuehn@cmu.edu; Simutin: 105 St. George Street, Toronto ON, M5S 3E6, mikhail.simutin@rotman.utoronto.ca; Wang: 5000 Forbes Avenue, Pittsburgh, PA 15213, jiaxuwang@cmu.edu. 


\section{Introduction}

Dynamics in the labor market are an integral component of business cycles. More than 10 percent of U.S. workers separate from their employers each quarter. Some move directly to a new job with a different employer, some become unemployed and some exit the labor force. These large flows are costly for firms because they need to spend resources to search for and train new employees. ${ }^{1}$

Building on the seminal contributions of Diamond (1982), Mortensen (1982), and Pissarides (1985), we show that labor search frictions are an important determinant of the crosssection of equity returns. ${ }^{2}$ In search models, firms post vacancies to attract workers, and unemployed workers look for jobs. The likelihood of matching a worker with a vacant job is determined endogenously and depends on the congestion of the labor market which is measured as the ratio of vacant positions to unemployed workers. This ratio, termed labor market tightness, is the key variable of our analysis. Intuitively, a higher ratio indicates tighter labor markets so that recruiting new workers becomes more costly.

We begin by studying the empirical relation between labor market conditions and the cross-section of equity returns. We measure aggregate labor market tightness as the ratio of the monthly vacancy index published by the Conference Board to the unemployed population (cf. Shimer (2005)). To measure the sensitivity of firm value to labor market conditions, we estimate loadings of equity returns on log changes in labor market tightness controlling for the market return. We use rolling regressions based on three years of monthly data to allow for time variation in the loadings. Using the panel of U.S. stock returns from 1954 to 2012, we show that the loadings on changes in the labor market tightness robustly and negatively relate to future stock returns in the cross-section. Sorting stocks into deciles on the estimated loadings, we find an average spread in future returns of firms in the low- and high-loading portfolios of $6 \%$ per year. We emphasize that this return differential is not due to

\footnotetext{
${ }^{1}$ According to the U.S. Department of Labor, it costs one-third of a new hire's annual salary to replace them. Direct costs include advertising, sign on bonuses, headhunter fees and overtime. Indirect costs include recruitment, selection and training and decreased productivity while current employees pick up the slack.

${ }^{2}$ The importance of labor market dynamics for the business cycle has long been recognized, e.g., Merz (1995) and Andolfatto (1996).
} 
mispricing. While it cannot be attributed to differences in loadings on commonly considered risk factors, such as those of the CAPM or the Fama and French (1993) three-factor model, it arises rationally in our theoretical model due to risk associated with labor market frictions as we describe in detail below.

To ensure that the relation between labor search frictions and future stock returns is not attributable to firm characteristics that are known to relate to future returns, we run Fama-MacBeth (1973) regressions of stock returns on lagged estimated loadings and other firm attributes. We include conventionally used control variables such as a firm's market capitalization and recently documented determinants of the cross-section of stock returns that may potentially correlate with the estimated loadings, such as hiring rates studied by Belo, Lin, and Bazdresch (2013). The Fama-MacBeth analysis confirms the robustness of results obtained in portfolio sorts. The coefficients on the labor market tightness loadings are negative and statistically significant in all regression specifications. The magnitude of the coefficients suggests that the relation is economically important: For each one standard deviation increase in the loading, subsequent annual returns decline by approximately $1.5 \%$.

Unlike many cross-sectional predictors of equity returns that are priced within rather than across industries, labor market tightness loadings contain valuable information about future returns when considered both within and across industries. In other words, the $6 \%$ return differential we observe when allowing for industry heterogeneity across portfolios sorted on labor market tightness loadings is a convex combination of firm-specific and industry-wide components. We estimate that the firm-specific element reaches $4.0 \%$ per year whereas the industry component stands at $3.1 \%$.

To interpret the empirical findings, we propose a labor market augmented capital asset pricing model. Building on the search framework pioneered by Diamond-MortensenPissarides, we build a partial equilibrium labor search model and study its implications for firm employment policies and stock returns. For tractability we do not model the supply of labor as an optimal household decision; instead we assume an exogenous pricing kernel. Our model features a cross-section of firms with heterogeneity in their idiosyncratic profitability 
shocks and employment levels. ${ }^{3}$ Under this pricing kernel, firms maximize their value either by posting vacancies to recruit workers or by firing workers to downsize. Both firm policies are costly at proportional rates.

In the model, the fraction of successfully filled vacancies depends on labor market conditions as measured by labor market tightness (the ratio of vacant positions to unemployed workers). As more firms post vacancies, it becomes less likely that vacant positions are filled, thereby increasing the expected recruiting costs to hire new workers. Since labor market tightness is a function of firms' vacancy policies, it has to be consistent with firm policies and is thus determined as an equilibrium outcome. In equilibrium, the matching of unemployed workers and firms is imperfect which results in both equilibrium unemployment and rents. These rents are shared between each firm and its workforce according to a Nash bargaining wage rate.

Our model is driven by two aggregate shocks, both of which are priced. The first shock is an aggregate productivity shock which proxies for the market return. The second shock is a shock to the efficiency of the matching technology which was first studied by Andolfatto (1996). The literature has shown that variation in matching efficiency can arise for many reasons, and we are agnostic about the exact source. For example, Pissarides (2011) emphasizes that matching efficiency captures the mismatch between the skill requirements of jobs and the skill mix of the unemployed, the differences in geographical location between jobs and unemployed, and the institutional structure of an economy with regard to the transmission of information about jobs.

Both aggregate productivity and matching efficiency are not directly observable in the data. Since we would like to quantitatively compare the model with the data, we map aggregate productivity and matching efficiency into the market return and labor market tightness which are observable in the data. As a result, we show that expected excess returns obey a two factor structure in the market return and labor market tightness. We call the resulting model the Labor Capital Asset Pricing Model.

\footnotetext{
${ }^{3}$ The canonical search and matching model is Mortensen and Pissarides (1994). More recently, firm heterogeneity in the search framework has been introduced by Cooper, Haltiwanger, and Willis (2007), Mortensen (2010), Elsby and Michaels (2013), and Fujita and Nakajima (2013).
} 
Quantitatively, our model replicates the negative relation between loadings on labor market tightness and future returns. Firms ideally would like to expand their workforce when the labor market is not congested, i.e., after positive shocks to the matching efficiency. These are times when the expected hiring costs are low. We assume that shocks to matching efficiency carry a negative price of risk, implying procyclical discount rates. This assumption is consistent with the general equilibrium view that positive efficiency shocks lead to lower consumption growth.

As an equilibrium outcome of the labor market, labor market tightness is positively related to matching efficiency shocks because in the model the cost channel dominates the discount rate effect. Consequently, firms with negative loadings on labor market tightness also have negative return exposure to matching efficiency shocks. Intuitively, firms that have to recruit workers after a negative matching efficiency shock have strongly countercyclical cash flows as higher recruiting costs reduce profits. As a result, these firms are riskier and require higher risk premia as their cash flows are not hedged against variation in matching efficiency.

Our paper builds on the production-based asset pricing literature started by Cochrane (1991) and Jermann (1998). Pioneered by Berk, Green, and Naik (1999), a large literature studies cross-sectional asset pricing implications of firm real investment decisions (e.g., Gomes, Kogan, and Zhang (2003), Carlson, Fisher, and Giammarino (2004), Zhang (2005), and Cooper (2006)). More closely related are Papanikolaou (2011), and Kogan and Papanikolaou (2012, 2013) who highlight that investment-specific shocks are related to firm risk premia. We differ by studying frictions in the labor market and specifically shocks to the efficiency of the matching technology.

The impact of labor market frictions on the aggregate stock market has been analyzed by Danthine and Donaldson (2002), Merz and Yashiv (2007), and Kuehn, Petrosky-Nadeau, and Zhang (2012). A related line of literature links cross-sectional asset prices to labor-related firm characteristics. Gourio (2007), Chen, Kacperczyk, and Ortiz-Molina (2011) and Favilukis and Lin (2012) consider labor operating leverage arising from rigid wages; Donangelo (2012) focuses on labor mobility; and Eisfeldt and Papanikolaou (2013) study organizational capital 
embedded in specialized labor input. We differ by exploring the impact of search costs on cross-sectional asset prices.

Closest to our paper is Belo, Lin, and Bazdresch (2013) who also emphasize that firms' hiring policies affect cross-sectional risk premia. They find that hiring growth rates predict returns in the data and explain this finding with a neoclassical Q-theory model on labor and capital adjustment costs. In contrast, we highlight the importance of search frictions in equilibrium labor markets. Recruiting workers in congested labor market is costly and firms' sensitivity to congested labor markets affects their valuation.

\section{Empirical Results}

In this section, we document a robust negative relation between stock return loadings on changes in labor market tightness and future equity returns. We establish this result by studying portfolios sorted by loadings on labor market tightness and confirm it using FamaMacBeth (1973) regressions. We also show that loadings on the factor forecast industry returns.

\section{A. Data}

Our sample includes all common stocks (share code of 10 or 11) listed on NYSE, AMEX, and Nasdaq (exchange code of 1, 2, or 3) available from CRSP. To obtain meaningful risk loadings at the end of month $t$, we require each stock to have non-missing returns in at least 24 of the last 36 months ( $t-35$ to $t$ ). Availability of data on vacancy and unemployment rates restricts our tests to the 1954-2012 period. Fama-MacBeth regressions additionally require Compustat data on book equity and other firm attributes. Consequently, the analysis based on those data is conducted for the 1960-2012 sample. In Appendix A we list the exact formulas for all of the firm characteristics used in our tests.

\section{B. Labor Market Tightness Factor}

We obtain the monthly vacancy index from the Conference Board and the monthly labor force participation and unemployment rates from the Current Population Survey of the Bureau of 
Labor Statistics. ${ }^{4}$ We define labor market tightness as the ratio of total vacancy postings to total unemployed workers. The total number of unemployed workers is the product of the unemployment rate and the labor force participation rate (LFPR). ${ }^{5}$ Hence labor market tightness is given by

$$
\theta_{t}=\frac{\text { Vacancy Index }_{t}}{\text { Unemployment Rate }_{t} \times \text { LFPR }_{t}} .
$$

Figure 1 plots the monthly time series of $\theta_{t}$ and its components. Labor market tightness is strongly procyclical and autocorrelated as in Shimer (2005). The cyclical nature of $\theta_{t}$ is driven by procyclicality of vacancies (the numerator of equation (1)) and countercyclicality of the number of unemployed workers (the denominator).

We define the labor market tightness factor in month $t$ as the change in logs of the vacancy-unemployment ratio $\theta_{t}$ :

$$
\vartheta_{t}=\log \left(\theta_{t}\right)-\log \left(\theta_{t-1}\right)
$$

The time series properties of $\vartheta_{t}$, its components and other macro variables are summarized in Table【. The labor market tightness factor is more volatile than any of the considered variables and has a mean that is statistically indistinguishable from zero. As expected, it is strongly correlated with its components. The factor is also highly correlated with default spread and changes in industrial production, which motivates us to conduct robustness tests (described below) to confirm that our empirical results are driven by changes in labor market tightness rather than by these other variables.

To study the relation between stock return sensitivity to changes in labor market tightness and future equity returns, we estimate loadings $\beta_{i, \tau}^{\theta}$ on the $\vartheta$ factor for each stock $i$ at the end of each month $\tau$ from rolling two-factor model regressions

$$
R_{i, t}-R_{f, t}=\alpha_{i, \tau}+\beta_{i, \tau}^{M}\left(R_{M, t}-R_{f, t}\right)+\beta_{i, \tau}^{\theta} \vartheta_{t}+\varepsilon_{i, t},
$$

\footnotetext{
${ }^{4}$ The respective websites are http://www.conference-board.org/data/helpwantedonline.cfm and http://www.bls.gov/cps. Help Wanted Advertising Index was discontinued in October 2008 and replaced with the Conference Board Help Wanted OnLine index. We concatenate the two time series to obtain the vacancy index. The index is not available after 2009 as the Conference Board replaced it with the actual number of online advertised vacancies. Barnichon (2010) proposes the methodology to construct the index through 2012 and maintains the data on his website, https://sites.google.com/site/regisbarnichon/research. We use his data to extend our sample until 2012.

${ }^{5}$ We use the seasonally adjusted unemployment rate to reduce predictable variation in the rate.
} 
where $R_{i, t}$ denotes the return on stock $i, R_{f, t}$ the risk-free rate, and $R_{M, t}$ the market return in month $t \in\{\tau-35, \tau\}$.

\section{Portfolio Sorts}

At the end of each month $\tau$, we rank stocks into deciles by loadings on the labor market

tightness factor $\beta_{i, \tau}^{\theta}$ computed from regressions (3). We skip a month to allow information on the vacancy and unemployment rates to become publicly available and hold the resulting ten value-weighted portfolios without rebalancing for one year $(\tau+2$ through $\tau+13$, inclusive). Consequently, in month $\tau$ each decile portfolio contains stocks that were added to that decile at the end of months $\tau-13$ through $\tau-2$. This design is similar to the approach used to construct momentum portfolios and ensures that noise due to seasonalities is reduced. We show robustness to alternative portfolio formation methods in the next section.

Table II presents average firm characteristics of the resulting decile portfolios. Average loadings on the labor market tightness factor $\left(\beta^{\theta}\right)$ range from -0.80 for the bottom decile to 0.91 for the top group. Firms in the high and low groups are on average smaller with higher market betas than firms in the other deciles, as is often the case when firms are sorted on estimated factor loadings. No strong relation emerges between loadings on the labor market tightness factor and any of the other considered characteristics: book-to-market ratios (BM), stock return runups (RU), asset growth rates (AG), investment rates (IR), and hiring rates $(\mathrm{HN})$. The lack of a relation between loadings on the labor market tightness factor and hiring rates is of particular interest, as it provides the first evidence that our empirical results are distinct from those of Belo, Lin, and Bazdresch (2013).

For each decile portfolio, we obtain monthly time series of returns from January 1954 until December 2012. Table III summarizes raw returns of each decile and of the portfolio that is long the decile with low loadings on the labor market tightness factor and short the group with high loadings. Table III also shows loadings on market (MKT), value (HML), size (SMB), and momentum (UMD) betas of each group. Firms in the high decile have somewhat larger size betas and lower momentum loadings. To control for differences in risk across the deciles, we also present unconditional alphas from the CAPM, Fama and French (1993) 3- 
factor model, and Carhart (1997) 4-factor model. In Tables AI and AII of the Appendix, we also show robustness to controlling for the liquidity and profitability factors, and summarize post-ranking loadings $\beta^{\vartheta}$ of the decile portfolios. Finally, to account for the possible time variation in betas and risk premiums, we calculate conditional alphas following either Ferson and Schadt 1996) (FS) or Boguth, Carlson, Fisher, and Simutin (2011) (BCFS). ${ }^{6}$

Both raw and risk-adjusted returns of the ten portfolios indicate a strong negative relation between loadings on the labor market tightness factor and future stock performance. Firms in the low $\beta^{\theta}$ decile earn the highest average return, $1.12 \%$ monthly, whereas the high-beta group performs most poorly, generating on average just $0.65 \%$ per month. The difference in performance of the two deciles, at $0.47 \%$, is economically large and statistically significant ( $t$ statistic of 3.41). The corresponding differences in both unconditional and conditional alphas are similarly striking, ranging from $0.41 \%$ ( $t$-statistic of 2.99 ) for Carhart 4 -factor alphas to $0.52 \%$ ( $t$-statistic of 3.83) for Fama-French 3-factor alphas.

Results of portfolio sorts thus strongly suggest that loadings on the labor market tightness factor are an important predictor of future returns. To evaluate robustness of this relation over time, Panel A of Figure 2 plots cumulative returns of the portfolio that is long the low decile and short the high group. The cumulative return is steadily increasing throughout the sample period, indicating that the relation between the loadings on the labor market tightness factor and future stock returns persists over time. Table IV presents summary statistics for returns on this portfolio and for market, value, size, and momentum factors. The long-short labor market tightness factor portfolio is as volatile as the market and the momentum factors (see also Panel B of Figure 2) and achieves a Sharpe ratio (0.13) comparable to that of the market and the value factors.

We emphasize that although the difference in returns of firms with low and high loadings

${ }^{6}$ More specifically, we calculate conditional alphas as intercepts from regression

$$
R_{j, t}-R_{f, t}=\alpha_{j}+\beta_{j}\left[\begin{array}{ll}
1 & Z_{t-1}
\end{array}\right]^{\prime}\left(R_{M, t}-R_{f, t}\right)+e_{j, \tau},
$$

where $j$ indexes portfolios, $t$ indexes months, $\beta_{j}$ is a $1 \times(k+1)$ parameter vector, and $Z_{t-1}$ is a $1 \times k$ instrument vector. Ferson and Schadt (FS) conditional alpha is computed using as instruments demeaned dividend yield, term spread, T-bill rate, and default spread. Boguth, Carlson, Fisher, and Simutin (BCFS) conditional alpha is computed by additionally including as instruments lagged 6- and 36-month market returns and average lagged 6- and 36-month betas of the portfolios. 
on the labor market tightness factor cannot be explained by the commonly considered factor models, this difference should not be interpreted as mispricing. It arises rationally in our theoretical framework as compensation for risk associated with labor market frictions. The commonly used factor models such as the CAPM do not capture this type of risk. Consequently, alphas from such models are different for firms with different loadings on the labor market tightness factor.

\section{Robustness of Portfolio Sorts}

We now demonstrate robustness of the relation between stock return loadings on changes in labor market tightness and future equity returns. We consider alternative portfolio formation approaches, i.e., we exclude micro cap stocks, use modified definitions of the labor market tightness factor, and modify regression (3) to also include size, value, and momentum factors. Table $\mathrm{V}$ summarizes the results of the robustness tests.

Portfolio formation design employed in the previous section is motivated by investment strategies such as momentum studied the prior literature. It involves holding 12 overlapping portfolios and ensures that noise due to seasonalities is reduced. We consider two alternatives: forming portfolios only once a year (Panel A) and holding the portfolios for one month (Panel B). Both alternatives ensure that no portfolios overlap. Panels A and B of Table $\mathrm{V}$ show that each of these approaches results in even more dramatic differences in future performance of low and high $\beta^{\theta}$ deciles. For example, the difference in average returns of the low and high groups reaches $0.55 \%$ monthly when portfolios are formed once a year, compared to $0.47 \%$ reported in Table III.

We next explore the sensitivity of the results to the length of time between calculation of $\beta^{\theta}$ and beginning of the portfolio formation. Our base case results in Table III are obtained by assuming that all variables needed to compute labor market tightness (vacancy index, unemployment rate, and labor force participation rate) are publicly available within a month. The assumption is well-justified in the current markets, where the data for any month are typically available within days after the end of that month. To allow for a slower dissemination of data in the earlier sample, we consider a two-month waiting period. Panel $\mathrm{C}$ of Table $\mathrm{V}$ 
shows that the results are not sensitive to this change in the methodology. The difference in future returns of stocks with low and high loadings on the labor market tightness factor reaches $0.47 \%$ per month.

To account for the possibility that the negative relation between stock return loadings on changes in labor market tightness and future equity returns is driven by stocks with very high or low loadings, we confirm robustness to sorting firms into quintile portfolios rather than into deciles. Panel D of Table $\mathrm{V}$ shows that the difference in future returns of quintiles with low and high loadings is economically and statistically significant.

Panel E of Table $\mathrm{V}$ shows that the results are also robust to excluding microcaps, which we define as stocks with market equity below the 20th NYSE percentile. Microcaps on average represent just $3 \%$ of the total market capitalization of all stocks listed on NYSE, Amex, and Nasdaq, but they account for about $60 \%$ of the total number of stocks. Excluding these stocks from the sample does not meaningfully impact the results. ${ }^{7}$

We also evaluate robustness to two alternative definitions of the labor market tightness factor. Table $\left[\right.$ shows that $\vartheta_{t}$ as defined in equation (2) is correlated with changes in industrial production and other macro variables. To ensure that the relation between stock return loadings on the labor market tightness factor and future equity returns is not driven by these variables, our first alternative specification involves re-defining the labor market tightness factor as the residual $\tilde{\vartheta}_{t}$ from a time-series regression

$$
\vartheta_{t}=\gamma_{0}+\gamma_{1} I P_{t}+\gamma_{2} C P I_{t}+\gamma_{3} D Y_{t}+\gamma_{4} T B_{t}+\gamma_{5} T S_{t}+\gamma_{6} D S_{t}+\tilde{\vartheta}_{t}
$$

where $I P_{t}, C P I_{t}, D Y_{t}, T B_{t}, T S_{t}$, and $D S_{t}$ are changes in industrial production, changes in the consumer price index, the dividend yield, the T-bill rate, the term spread, and the default spread, respectively. Our second alternative definition calls for computing the labor market tightness factor as the residual from fitting the log of labor market tightness to an ARMA(1,1) model. The disadvantage of both of these approaches is that they introduce a look-ahead bias as the entire sample is used to estimate the labor market tightness factor. Yet, the first

\footnotetext{
${ }^{7}$ Untabulated results also confirm robustness to imposing a minimum price filter and to excluding Nasdaqlisted stocks.
} 
alternative definition allows us to focus on the component of labor market tightness that is unrelated to macro variables that may have non-zero prices of risk. And the second definition allows us to focus on the unpredictable component of labor market tightness. Panels $\mathrm{F}$ and $\mathrm{G}$ of Table $\mathrm{V}$ show that our results are little affected by the changes in the definition of the labor market tightness factor. The difference in future raw and risk-adjusted returns of portfolios with low and high loadings on the factor are always statistically significant and economically important, ranging between $0.41 \%$ and $0.51 \%$ monthly.

We have shown that the relation between loadings on the labor market factor and future equity returns is not driven by differences in loadings but captured by alphas (see Table III). Relatedly, we also consider modifying regression (3) to include size, value and momentum factors for robustness. Panel $\mathrm{H}$ of Table $\mathrm{V}$ shows that our results are not sensitive to this alternative method of estimating $\beta^{\theta}$.

Finally, we also evaluate the relation between loadings $\beta^{\theta}$ on the labor market tightness factor and future equity returns conditional on stocks' market betas $\beta^{M}$. We sort firms into quintiles based on their $\beta^{\theta}$ and $\beta^{M}$ loadings and study subsequent returns of each of the resulting 25 portfolios. Table AIII of the Appendix shows that irrespective of whether we consider independent sorts or dependent sorts (e.g., first on $\beta^{M}$ and then by $\beta^{\theta}$ within each market beta quintile), stocks with low loadings on the labor market tightness factor significantly outperform stocks with high loadings.

\section{E. Fama-MacBeth Regressions}

The empirical evidence from portfolio sorts provides a strong indication of a negative relation between the stock return loadings on changes in labor market tightness, $\beta^{\theta}$, and subsequent equity returns. However, such univariate analysis does not account for other firm characteristics that have been shown to relate to future returns. We compare the loadings on the labor market tightness factor to other well-established determinants of the cross-section of stock

returns. Our goal is to evaluate whether the ability of $\beta^{\theta}$ to forecast returns is subsumed by 
other firm characteristics. To this end, we run annual Fama-MacBeth (1973) regressions

$$
R_{i, T+1}=\gamma_{T}^{0}+\gamma_{T}^{1} \beta_{i, \tau}^{\theta}+\sum_{j=1}^{K} \gamma_{T}^{j} X_{i, T}^{j}+\eta_{i, T},
$$

where $R_{i, T+1}$ is stock $i$ return from July of year $T$ to June of year $T+1, \beta_{i, \tau}^{\theta}$ is the loading from regressions (3) with $\tau$ corresponding to May of year $T$, and $X_{i, T}$ are $K$ control variables all measured prior to the end of June of year $T$. The timing of the variable measurement in the regression follows the widely accepted convention as in Fama and French (1992).

We include in the Fama-MacBeth regressions commonly considered control variables such as the log of a firm's market capitalization (ME), the log of the book-to-market ratio (BM), and the return runup (RU) (Fama and French (1992); Jegadeesh and Titman (1993)). We also consider other recently documented determinants of the cross-section of stock returns, including the asset growth rate (AG) of Cooper, Gulen, and Schill (2008) as well as the labor hiring (HN) and investment rates (IK) of Belo, Lin, and Bazdresch (2013). We winsorize all independent variables cross-sectionally at $1 \%$ and $99 \%$.

Table VI summarizes the results of the Fama-MacBeth regressions. The coefficient on $\beta^{\theta}$ is negative and statistically significant in each considered specification, even after accounting for other predictors of the cross-section of equity returns. The magnitude of the coefficient implies that for a one standard deviation increase in $\beta^{\theta}(0.49)$, subsequent annual returns decline by approximately 1.5\%. Average loadings of firms in the bottom and top decile portfolios are 3.5 standard deviations apart, suggesting that the difference in future stock returns of the two groups exceeds $5 \%$ per year, in line with the results presented in Table III.

The labor market tightness factor is highly correlated with its components and with changes in industrial production (see Table II). To ensure that our results are not driven by either of these macro variables, we first estimate loadings from a two-factor regression of stock excess returns on market excess returns and log changes in either labor force participation rate $\left(\beta^{L F P R}\right)$, unemployment rate $\left(\beta^{U n e m p}\right)$, vacancy index $\left(\beta^{V a c}\right)$, or industrial production $\left(\beta^{I P}\right)$, respectively. These loadings are estimated in the same manner as is $\beta^{\theta}$ in equation (3). We next run Fama-MacBeth regressions of annual stock returns on lagged loadings $\beta^{L F P R}$, $\beta^{U n e m p}, \beta^{V a c}$, and $\beta^{I P}$ and on other control variables. Table $\mathrm{AV}$ of the Appendix shows that 
none of the considered loadings are robustly related to future equity returns, suggesting that the relation between loadings on the labor market tightness factor and future stock returns is not driven by one particular component of the labor market tightness or by changes in industrial production.

\section{F. Industry-Level Analysis}

The ability of commonly considered firm characteristics to predict stock returns is known to be stronger when these characteristics are computed relative to industry averages. In other words, many determinants of the cross-section of stock returns are priced within rather than across industries (e.g., Cohen and Polk (1998), Asness, Burt, Ross, and Stevens (2000), Simutin (2010), Novy-Marx (2011)). We now show that unlike many other cross-sectional predictors

of stock returns, $\beta^{\theta}$ contains better information about future returns when considered across rather than within industries. Our goal in this section is to understand how much of the negative relation between $\beta^{\theta}$ and future stock returns is due to industry-specific versus firmspecific (non-industry) components.

We begin our analysis by modifying the portfolio assignment methodology used above to ensure that all $\beta^{\theta}$ decile portfolios have similar industry characteristics. To achieve this, we sort firms into deciles within each of the 48 industries as defined by Ken French and then aggregate firms across industries to obtain ten industry-neutral portfolios. Panel A of Table VII shows that the differences in future performance of firms with low and high loadings on the labor market tightness factor are slightly muted relative to those in Table III. For example, the return of the Low-High portfolio reaches $0.36 \%$ monthly when portfolio assignment is done within industries, whereas the corresponding figure is $0.47 \%$ when industry composition is allowed to vary across deciles.

The larger difference in future performance of low and high $\beta^{\theta}$ stocks when we allow for industry heterogeneity across decile portfolios is particularly interesting given that many known premiums are largely intra-industry phenomena. This result suggests that the labor market tightness factor may be priced in the cross-section of industry portfolios. To investigate this conjecture, we assign 48 value-weighted industry portfolios into deciles on the basis of 
their loadings on the labor market tightness factor and study future returns of the resulting decile portfolios. Panel B of Table VII shows that industries with low loadings outperform industries with high loadings by between $0.34 \%$ per month. ${ }^{8}$

\section{Model}

The goal of this section is to provide an economic model, which explains the empirical link between labor market frictions and the cross-section of equity returns. To this end, we solve a partial equilibrium labor market model and study its implications for stock returns. For tractability we do not model endogenous labor supply decisions from households, instead we assume an exogenous pricing kernel.

\section{A. Revenue}

To focus on labor frictions, we assume that the only input to production is labor. We thus abstract from capital accumulation and investment frictions. Firms generate revenue, $Y_{i, t}$, according to a decreasing returns to scale production function

$$
Y_{i, t}=e^{x_{t}+z_{i, t}} N_{i, t}^{\alpha}
$$

where $\alpha$ denotes the labor share of production and $N_{i, t}$ is the size of the firm's workforce. Both the aggregate productivity shock $x_{t}$ and the idiosyncratic productivity shocks $z_{i, t}$ follow $\operatorname{AR}(1)$ processes

$$
\begin{aligned}
x_{t} & =\left(1-\rho_{x}\right) \bar{x}+\rho_{x} x_{t-1}+\sigma_{x} \varepsilon_{t}^{x}, \\
z_{i, t} & =\rho_{z} z_{i, t-1}+\sigma_{z} \varepsilon_{i, t}^{z},
\end{aligned}
$$

where $\varepsilon_{t}^{x}, \varepsilon_{i, t}^{z}$ are standard normal i.i.d. innovations. Firm-specific shocks are independent across firms, and from aggregate shocks.

The dynamics of firms' workforce are determined by optimal hiring and firing policies. Firms can expand the workforce by posting vacancies, $V_{i, t}$, to attract unemployed workers. The key friction of search markets is that not all the posted vacancies are filled in a given

\footnotetext{
${ }^{8}$ Industry portfolios are from Ken French's data library. Table AVI of the Appendix provides summary statistics for the industry portfolios.
} 
period. Instead, the rate $q$ at which vacancies are filled is endogenously determined in equilibrium and depends on the tightness of the labor market, $\theta_{t}$, and an exogenous efficiency shock, $p_{t}$, to the matching technology. Once workers and firms are randomly matched, a constant fraction $s$ of workers quit voluntarily and $F_{i, t}$ of them are laid off by the firm. Taken together, this implies the following law of motion for the firm workforce size

$$
N_{i, t+1}=(1-s) N_{i, t}+q\left(\theta_{t}, p_{t}\right) V_{i, t}-F_{i, t}
$$

The matching efficiency shock $p_{t}$ follows an $\operatorname{AR}(1)$ process with autocorrelation $\rho_{p}$ and i.i.d. normal innovation $\varepsilon_{t}^{p}$ which is uncorrelated with aggregate productivity innovations $\varepsilon_{t}^{x}$

$$
p_{t}=\rho_{p} p_{t-1}+\sigma_{p} \varepsilon_{t}^{p}
$$

This matching efficiency shock is common across firms and thus represents aggregate risk. This shock was first studied by Andolfatto (1996) who argued that it can be interpreted as a reallocative shock, distinct from disturbances that affect production technologies. In search models, the efficiency of the economy's allocative mechanism is captured by the technological properties of the aggregate matching function. Changes in this function can be thought of as reflecting mismatches in the labor market between the skills, geographical location, demography or other dimensions of unemployed workers and job openings across sectors, thereby causing a shift in the so-called aggregate Beveridge curve.

Several recent studies empirically analyze different channels that can explain changes in matching efficiency. Using micro-data Barnichon and Figura (2011) show that fluctuations in matching efficiency can be related to the composition of the unemployment pool, such as a rise in the share of long-term unemployed or fluctuations in participation due to demographic factors, and dispersion in labor market conditions; Herz and van Rens (2011) and Sahin, Song, Topa, and Violante (2012) highlight the role of skill and occupational mismatch between jobs and workers; Sterk (2010) focuses on geographical mismatch exacerbated by house price movements; and Fujita (2011) analyzes the role of reduced worker search intensity due to extended unemployment benefits. 


\section{B. Matching}

Labor market tightness, $\theta_{t}$, determines how easily vacant positions can be filled. It is measured as the ratio of aggregate vacancies, $\bar{V}_{t}$, to the aggregate unemployment level, $\bar{U}_{t}$, i.e., $\theta_{t}=$ $\bar{V}_{t} / \bar{U}_{t}$. The aggregate number of vacancies is simply the sum of all firm-level vacancies

$$
\bar{V}_{t}=\int V_{i, t} d \mu_{t}
$$

where $\mu_{t}$ denotes the time-varying distribution of firms over the firm-level state space $\left(z_{i, t}, N_{i, t}\right)$. The mass of firms is normalized to one. The labor force is defined as the sum of employed and unemployed with mass one. Thus, the total number of unemployed equals

$$
\bar{U}_{t}=1-(1-s) \int N_{i, t} d \mu_{t}
$$

Following den Haan, Ramey, and Watson (2000), vacancies are filled according to a constant returns to scale matching function

$$
\mathcal{M}\left(\bar{U}_{t}, \bar{V}_{t}, p_{t}\right)=\frac{e^{p_{t}} \bar{U}_{t} \bar{V}_{t}}{\left(\bar{U}_{t}^{\xi}+\bar{V}_{t}^{\xi}\right)^{1 / \xi}}
$$

and the rate $q$ at which vacancy are filled per unit of time can be computed from

$$
q\left(\theta_{t}, p_{t}\right)=\frac{\mathcal{M}\left(\bar{U}_{t}, \bar{V}_{t}, p_{t}\right)}{\bar{V}_{t}}=e^{p_{t}}\left(1+\theta_{t}^{\xi}\right)^{-1 / \xi}
$$

The matching rate is decreasing in $\theta$, meaning that an increase in the relative scarcity of unemployed workers relative to job vacancies makes it more difficult for firms to fill a vacancy, and increasing in $p$, as a positive efficiency shock makes finding a worker easier.

\section{Wages}

In equilibrium, the matching of unemployed workers and firms is imperfect, which results in both equilibrium unemployment and rents. These rents are shared between each firm and its workforce according to a Nash bargaining wage rate. Following Stole and Zwiebel (1996), we derive the Nash bargaining wage in multi-worker firms with decreasing returns to scale production technology. Specifically, firms renegotiate wages every period with its workforce based on individual (and not collective) Nash bargaining. 
In the bargaining process, workers have bargaining weight $\eta \in(0,1)$. If workers decide not to work, they receive unemployment benefits $b$, which represent the value of their outside option. They are also rewarded the saving of hiring costs that firms enjoy when a job position is filled, $\kappa_{h} \theta_{t}$, where $\kappa_{h}$ is the unit cost of vacancy posting. As a result, wages are given by ${ }^{9}$

$$
w_{i, t}=\eta\left[\frac{\alpha}{1-\eta(1-\alpha)} \frac{Y_{i, t}}{N_{i, t}}+\kappa_{h} \theta_{t}\right]+(1-\eta) b
$$

Firms benefit from hiring the marginal worker not only through an increase in output by the marginal product of labor but also through a decrease in wage payment to all the existing workers, $Y_{i, t} / N_{i, t}$. The term $\alpha /(1-\eta(1-\alpha))$ represents a reduction in wages coming from decreasing returns to scale. At the same time, workers can extract higher wages from firms when the labor market is tighter. Unemployment benefits provide a floor to wages. ${ }^{10}$

\section{Firm Value}

We do not model the supply side of labor coming form households. This would require to solve a full general equilibrium model. Instead, following Berk, Green, and Naik (1999), we specify an exogenous pricing kernel and assume that both the aggregate productivity shock $x_{t}$ and efficiency shock $p_{t}$ are priced. The log of the pricing kernel is given by

$$
\ln M_{t+1}=\ln \beta-\gamma_{x}\left(\sigma_{x} \varepsilon_{t+1}^{x}+\phi x_{t}\right)-\gamma_{p, t}\left(\sigma_{p} \varepsilon_{t+1}^{p}+\phi p_{t}\right)
$$

where $\beta$ is the time discount rate, $\gamma_{x}$ the constant price of aggregate productivity shocks, $\gamma_{p, t}=\gamma_{p, 0} e^{\gamma_{p, 1} p_{t}}$ the time-varying price of efficiency shocks, and $\phi$ measures the sensitivity of interest rates with respect to aggregate shocks.

The objective of firms is to maximize their value $S_{i, t}$ either by posting vacancies $V_{i, t}$ to hire workers or by firing $F_{i, t}$ employed workers to downsize. Both adjustments are costly at a rate $\kappa_{h}$ for hiring and $\kappa_{f}$ for firing. Firms also pay fixed operating costs $f$. Dividends to shareholders are given by revenues net of operating, hiring, and firing costs as well as wage payments

$$
D_{i, t}=Y_{i, t}-f-w_{i, t} N_{i, t}-\kappa_{h} V_{i, t}-\kappa_{f} F_{i, t} .
$$

\footnotetext{
${ }^{9}$ See Appendix B for the derivation.

${ }^{10}$ The same wage process is assumed in Elsby and Michaels (2013) and Fujita and Nakajima (2013).
} 
The firm's Bellman equation solves

$$
S_{i, t}=\max _{V_{i, t} \geq 0, F_{i, t} \geq 0}\left\{D_{i, t}+\mathbb{E}_{t}\left[M_{t+1} S_{i, t+1}\right]\right\}
$$

subject to equations (7)-(17). Notice that the firm's problem is well-defined given labor market tightness $\theta_{t}$ and an expectation about how it evolves. Given optimal (cum-dividend) firm value $S_{i, t}$, expected stock returns are

$$
\mathbb{E}_{t}\left[R_{i, t+1}\right]=\frac{\mathbb{E}_{t}\left[S_{i, t+1}\right]}{S_{i, t}-D_{i, t}}
$$

\section{E. Equilibrium}

Optimal firm employment policies depend on the dynamics of the labor market equilibrium. More specifically, the probability $q$, of a vacancy being filled with a worker, is a function of aggregate labor market tightness $\theta$ and matching efficiency $p$. Each individual firm is atomistic and takes labor market tightness as exogenous.

Let $\Omega_{i, t}=\left(N_{i, t}, z_{i, t}, x_{t}, p_{t}, \mu_{t}\right)$ be the vector of state variables and $\Gamma$ be the law of motion for the time-varying firm distribution $\mu_{t}$,

$$
\mu_{t+1}=\Gamma\left(\mu_{t}, x_{t+1}, x_{t}, p_{t+1}, p_{t}\right)
$$

A given distribution $\mu_{t}$ of the firm-level state space together with the aggregate shocks implies a value for labor market tightness $\theta_{t}$. Hence, equilibrium in the labor market requires that labor market tightness $\theta_{t}$ at each date is determined as a fixed point satisfying

$$
\theta_{t}=\frac{\int V\left(\Omega_{i, t}\right) d \mu_{t}}{1-\int N_{i, t} d \mu_{t}}
$$

The recursive competitive equilibrium is characterized by: $(i)$ labor market tightness $\theta_{t}$, (ii) optimal firm policies $V\left(\Omega_{i, t}\right), F\left(\Omega_{i, t}\right)$, and firm value function $S\left(\Omega_{i, t}\right)$, (iii) a law of motion of firm distribution $\Gamma$, such that: Optimality: Given the pricing kernel (17), Nash bargaining wage rate (16), and labor market tightness $\theta_{t}, V\left(\Omega_{i, t}\right)$ and $F\left(\Omega_{i, t}\right)$ solve the firm's Bellman equation (19) where $S\left(\Omega_{i, t}\right)$ is its solution; Consistency: $\theta_{t}$ is consistent with the labor market equilibrium (22), and the law of motion of firm distribution $\Gamma$ is consistent with the optimal firm policies $V\left(\Omega_{i, t}\right)$ and $F\left(\Omega_{i, t}\right)$. 


\section{F. Approximate Aggregation}

The firm's hiring and firing decisions trade off current costs and future benefits, which depend on the aggregation and evolution of the firm distribution. Rather than solving for the high dimensional firm distribution $\mu_{t}$ exactly, we follow Krusell and Smith (1998) and approximate the firm-level distribution with one moment. In search models, labor market tightness $\theta_{t}$ is a sufficient statistic to solve the firm's problem 19 and thus enters the state vector replacing $\mu_{t}$, i.e., the approximate state space is $\tilde{\Omega}_{i, t}=\left(N_{i, t}, z_{i, t}, x_{t}, p_{t}, \theta_{t}\right)$.

To approximate the law of motion $\Gamma$ in equation (21), we assume a log-linear functional form

$$
\log \theta_{t+1}=\tau_{0}+\tau_{\theta} \log \theta_{t}+\tau_{x} \varepsilon_{t+1}^{x}+\tau_{p} \varepsilon_{t+1}^{p}
$$

Under rational expectations, the perceived labor market outcome equals the realized one at each date of the recursive competitive equilibrium. In equilibrium, we can express the labor market tightness factor $\vartheta$ as the change in logs of labor market tightness

$$
\vartheta_{t+1}=\tau_{0}+\left(\tau_{\theta}-1\right) \log \theta_{t}+\tau_{x} \varepsilon_{t+1}^{x}+\tau_{p} \varepsilon_{t+1}^{p}
$$

This definition is consistent with our empirical exercise in Section II

Our application of Krusell and Smith (1998) differs from Zhang (2005) along two dimensions. First, we model future labor market tightness, $\theta_{t+1}$, as a function of the firm distribution at time $t+1$; hence, it is not in the information set of date $t$. The forecasting rule (23) at time $t$ does not enable firms to learn $\theta_{t+1}$ perfectly, but rather to form a rational expectation about $\theta_{t+1}$. In contrast, Zhang (2005) assumes that firms can perfectly forecast next period's industry price given time $t$ states. If firms could perfectly forecast next period's labor market tightness, it would not carry a risk premium.

Second, at each period of the simulation, we impose labor market equilibrium by solving $\theta_{t}$ as the fixed point in Equation (22). Hence, there is no discrepancy between the forecasted and the realized $\theta_{t+1}$. 


\section{G. Equilibrium Risk Premia}

The model is driven by two aggregate shocks: aggregate productivity and matching efficiency. To test the model's cross-sectional return implications on data, it is advantageous to derive an approximate linear pricing model. Based on the Euler equation for expected excess returns, we can apply a log-linear approximation to the pricing kernel (17) implying

$$
\mathbb{E}_{t}\left[R_{i, t+1}^{e}\right] \approx \beta_{i, t}^{x} \lambda^{x}+\beta_{i, t}^{p} \lambda_{t}^{p}
$$

where $\beta_{i, t}^{x}$ and $\beta_{i, t}^{p}$ are loadings on aggregate productivity and matching efficiency shocks and $\lambda^{x}$ and $\lambda_{t}^{p}$ are their respective factor risk premia. ${ }^{11}$

Both aggregate productivity and matching efficiency are not directly observable in the data. Since we would like to take the model to the data, it is necessary to express expected excess returns in terms of observable variables such as the return on the market and labor market tightness. To this end, we also approximate the return on the market as an affine function of the aggregate shocks

$$
R_{M, t+1}^{e}=\nu_{0}+\nu_{x} \varepsilon_{t+1}^{x}+\nu_{p} \varepsilon_{t+1}^{p}
$$

As a result, we can show that expected excess returns obey a two-factor structure in the market return and labor market tightness which is summarized in the following proposition.

Proposition 1 Given a log-linear approximation to the pricing kernel (17) and laws of motion (24) and (26), the log pricing kernel satisfies

$$
m_{t+1}=-\gamma_{M, t} R_{M, t+1}^{e}-\gamma_{\theta, t} \vartheta_{t+1},
$$

where the prices of market risk $\gamma_{M}$ and labor market tightness $\gamma_{\theta}$ are given by

$$
\gamma_{M, t}=\frac{\tau_{p} \gamma_{x}-\tau_{x} \gamma_{p, t}}{\tau_{p} \nu_{x}-\tau_{x} \nu_{p}} \quad \gamma_{\theta, t}=\frac{\nu_{x} \gamma_{p, t}-\nu_{p} \gamma_{x}}{\tau_{p} \nu_{x}-\tau_{x} \nu_{p}}
$$

The pricing kernel (27) implies a linear pricing model in the form of

$$
\mathbb{E}_{t}\left[R_{i, t+1}^{e}\right]=\beta_{i, t}^{M} \lambda_{t}^{M}+\beta_{i, t}^{\theta} \lambda_{t}^{\theta},
$$

\footnotetext{
${ }^{11}$ All proofs of this section can be found in Appendix C.
} 
where $\beta_{i, t}^{M}$ and $\beta_{i, t}^{\theta}$ are the loadings on the market return and log-changes of labor market tightness

$$
\begin{aligned}
\beta_{i, t}^{M} & =\frac{\tau_{p}}{\tau_{p} \nu_{x}-\tau_{x} \nu_{p}} \beta_{i, t}^{x}+\frac{-\tau_{x}}{\tau_{p} \nu_{x}-\tau_{x} \nu_{p}} \beta_{i, t}^{p} \\
\beta_{i, t}^{\theta} & =\frac{-\nu_{p}}{\tau_{p} \nu_{x}-\tau_{x} \nu_{p}} \beta_{i, t}^{x}+\frac{\nu_{x}}{\tau_{p} \nu_{x}-\tau_{x} \nu_{p}} \beta_{i, t}^{p}
\end{aligned}
$$

and $\lambda_{t}^{M}$ and $\lambda_{t}^{\theta}$ are the respective factor risk premia given by

$$
\lambda_{t}^{M}=\nu_{x} \lambda^{x}+\nu_{p} \lambda_{t}^{p} \quad \lambda_{t}^{\theta}=\tau_{x} \lambda^{x}+\tau_{p} \lambda_{t}^{p}
$$

We call relation (29) the Labor Capital Asset Pricing Model. ${ }^{12}$ The goal of the model is to endogenously generate a negative factor risk premium of labor market tightness, $\lambda_{t}^{\theta}$. We will explain the intuition behind Proposition 1 after the calibration in Section IV.B.

In the data, the CAPM cannot explain the returns of portfolios sorted by loadings on labor market tightness, $\beta_{i, t}^{\theta}$. To replicate this failure of the CAPM in the model, we can compute a mis-specified one-factor CAPM and compare the CAPM implied alphas with the data. The following proposition summarizes this idea.

Proposition 2 Given a log-linear approximation to the pricing kernel (17) and laws of motion (24) and (26), the CAPM implies a linear pricing model in the form of

$$
\mathbb{E}_{t}\left[R_{i, t+1}^{e}\right]=\alpha_{i, t}^{C A P M}+\beta_{i, t}^{C A P M} \lambda_{t}^{C A P M}
$$

where the CAPM mispricing alphas are given by

$$
\alpha_{i, t}^{C A P M}=\beta_{i, t}^{\theta} \gamma_{\theta, t} \frac{\left(\tau_{x} \nu_{p}-\nu_{x} \tau_{p}\right)^{2} \sigma_{p}^{2} \sigma_{x}^{2}}{\nu_{x}^{2} \sigma_{x}^{2}+\nu_{p}^{2} \sigma_{p}^{2}},
$$

CAPM loadings on the market return by

$$
\beta_{i, t}^{C A P M}=\frac{\nu_{x} \sigma_{x}^{2}}{\nu_{x}^{2} \sigma_{x}^{2}+\nu_{p}^{2} \sigma_{p}^{2}} \beta_{x}+\frac{\nu_{p} \sigma_{p}^{2}}{\nu_{x}^{2} \sigma_{x}^{2}+\nu_{p}^{2} \sigma_{p}^{2}} \beta_{p},
$$

and the CAPM factor risk premium $\lambda_{t}^{C A P M}=\lambda_{t}^{M}=\nu_{x} \lambda^{x}+\nu_{p} \lambda_{t}^{p}$.

\footnotetext{
${ }^{12}$ Note, that the risk loadings 30 and 31 are not univariate regression betas because the market return and labor market tightness are correlated.
} 


\section{Quantitative Results}

In this section, we describe our calibration procedure and the benchmark parameterization. We first present the numerical results of the equilibrium forecasting rules. Given the equilibrium dynamics for the labor market, we calculate theoretical loadings on labor market tightness and show that the model is consistent with the inverse relation between loadings and expected future stock returns in the cross-section. At the end of this section, we discuss the main mechanism driving our model.

We solve the competitive equilibrium numerically in the discretized state space $\Omega_{i, t}$ using an iterative algorithm described in Appendix D. Given the equilibrium forecasting rule, firms make optimal employment decisions. We simulate a panel of 5,000 firms for 5,000 periods.

\section{A. Calibration}

This section describes how we calibrate the parameter values. We adopt a monthly frequency because labor market and equity market data are available at that frequency. Table VIII summarizes the parameter calibration of the benchmark model.

The labor literature provides several empirical studies to calibrate the labor market parameters. According to Davis, Faberman, and Haltiwanger (2006) and Davis, Faberman, Haltiwanger, and Rucker (2010), the monthly total separation rate measured in the Job Openings and Labor Turnover Survey (JOLTS) by the BLS is around 4\%. The total separation rates captures both voluntary quits and involuntary layoffs. As firms in our model can optimize over the number of worker to be laid off, we calibrate the separation rate only to the voluntary quit rate which captures workers switching jobs, for instance, for reasons of career development, better pay or preferable working conditions. We set the monthly exogenous quit rate $s$ at $2.2 \%$ so that the model is consistent in steady state with the hiring and layoff rate reported by JOLTS.

The elasticity of the matching function determines how quickly the vacancy filling rate falls as a function of labor market tightness. Based on the structural estimate in den Haan, Ramey, and Watson (2000), we set the elasticity $\xi$ at 1.27. This number is also in line with Shimer 
(2005) who finds that the aggregate monthly job finding rate $f$ equals 0.45 and the average vacancy filling rate $q=0.71$. In steady state, labor market tightness equals $f / q=0.634$ and the vacancy filling rate is given by $q=\left((f / q)^{\xi}+1\right)^{-1 / \xi}$ which implies $\xi=1.28$.

The bargaining power of workers $\eta$ determines the rigidity of wages over the business cycle. As emphasized in Hagedorn and Manovskii (2008), the elasticity of aggregate wages with respect to labor productivity is only 0.45 in the data, meaning, that wages are half as volatile as labor productivity. Similarly, Gertler and Trigari (2009) find that the relative volatility of wages to output is 0.52 in the data. We follow their calibration strategy and set $\eta$ at 0.10 to match the relative volatility of wages to output. ${ }^{13}$ It is important to highlight that our model is not driven by sticky wages as proposed by Hall (2005) and Gertler and Trigari (2009). In our model, wages are less volatile than productivity but, conditional on productivity, they are not sticky. This is consistent with Pissarides (2009) who argues that Nash bargaining wage rates are in line with wages for new hires.

If workers decide not to work, they receive the flow value of unemployment activities b. Shimer (2005) argues that the outside option for rejecting a job offer are unemployment benefits and thus sets $b=0.4$. Hagedorn and Manovskii (2008), on the other hand, claim that unemployment activities capture not only unemployment benefits but also utility from home production and leisure. They calibrate $b$ close to one. As in the calibration of Pissarides (2009), we follow Hall and Milgrom (2008) and set the value of unemployment activities at $0.75 .^{14}$

The labor share of income, which Gomme and Rupert (2007) estimate to be around 0.72, is highly affected by the value of unemployment activities $b$ as well as the labor elasticity of output $\alpha$. Since the value of unemployment activities is close to the labor share of income, we can easily match the labor share by setting the labor elasticity of output $\alpha$ at 0.75 . We assume less curvature in the production function than, for instance, Cooper, Haltiwanger, and Willis (2007). They, however, do not model wages as the outcome of Nash bargaining.

\footnotetext{
${ }^{13}$ Hagedorn and Manovskii (2008) set the bargaining power of workers at 0.054 and Lubik (2009) estimates it to be 0.03 .

${ }^{14}$ Similarly, Lubik (2009) estimates that unemployment activities amount to 0.74 relative to unit mean labor productivity.
} 
The proportional costs of hiring and firing workers, $\kappa_{h}$ and $\kappa_{f}$, determine both the overall costs of adjusting the workforce as well as the behavior of firm policies. Since estimates of hiring costs are sparse, we set $\kappa_{h}$ at 0.4 to match the aggregate hiring rate of workers. Our parameter choice is close to Hall and Milgrom (2008) who account for both the capital costs of vacancy creation and the opportunity cost of labor effort devoted to hiring activities.

Employment protection legislations are a set of rules and restrictions governing the dismissals of employees. Such provisions impose a firing cost to the firm that has two separate dimensions: a transfer from the firm to the worker to be laid off (e.g., severance payments), and a tax to be paid outside the job-worker pair (e.g., legal expenses). As the labor search literature does not provide guidance for the magnitude of this parameter, we set the flow costs of firing workers $\kappa_{f}$ to match the aggregate layoff rate.

Without fixed operating costs, the model would overstate the net profit margin of firms. Similarly, without proportional operating costs, the model implied aggregate unemployment would be unrealistically small. Consequently, we target the aggregate profit to aggregate output ratio and the unemployment rate to calibrate fixed $f_{0}$ and proportional $f_{1}$ operating costs.

We calibrate the two aggregate shocks following the macroeconomics literature. Since labor is the only input to production, the aggregate productivity is typically measured as aggregate output relative to the labor hours used in the production of that output. As such, labor productivity is more volatile than total factor productivity. Similar to Gertler and Trigari (2009), we set $\rho_{x}=0.95^{1 / 3}$ and $\sigma_{x}=0.005$. Shocks to the matching efficiency tend to be less persistent but more volatile than labor productivity shocks. For instance, Andolfatto (1996) estimates matching shocks to have persistence of 0.85 with innovation volatility of 0.07 at quarterly frequency. We follow more recent estimates by Cheremukhin and RestrepoEchavarria (2010) and set $\rho_{p}=0.88^{1 / 3}$ and $\sigma_{p}=0.025 .{ }^{15}$

For the persistence $\rho_{z}$ and conditional volatility $\sigma_{z}$ of firm-specific productivity, we choose values close to those used by Zhang (2005), Gomes and Schmid (2010), and Fujita and Naka\begin{tabular}{l}
\hline \hline${ }^{15}$ Similar structural estimates are contained in \\
\hline$(2012)$ Furlanetto and Groshenny $(2012)$ and
\end{tabular} 
jima (2013) to match the cross-sectional properties of firm hiring policies.

The pricing kernel is calibrated to match financial moments. We choose the time discount rate $\beta$ and the pricing kernel parameters $\gamma_{x}, \gamma_{p, 0}, \gamma_{p, 1}, \phi$ so that the model approximately matches the first and second moments of the risk-free rate and market return. This requires that $\beta$ equals $0.9935, \gamma_{x}=1, \gamma_{p, 0}=-5, \gamma_{p, 1}=5$, and $\phi=-0.0225$. Importantly, shocks to matching efficiency carry a negative price of risk and are pro-cyclical. A small parameter value of $\phi$ allows for a time-varying but smooth interest rate.

Berk, Green, and Naik (1999) provide a motivation for $\gamma_{x}>0$ in an economy with only aggregate productivity shocks. The assumption of $\gamma_{p}<0$ can be motivated as follows. In a general equilibrium economy with a representative household, a positive matching function efficiency shock increases the probability that vacant jobs are filled and thereby lowers the expected unit hiring cost. As a result, job creation becomes more attractive and firms spend more resources on hiring workers, thus depressing aggregate consumption. ${ }^{16}$

Table IX] summarizes aggregate moments computed on simulated data of the model. The data for the unemployment rate are from the BLS, the hiring and layoff rates are from the JOLTS dataset collected by the BLS, the labor share of income is from Gomme and Rupert (2007), the volatility of aggregate wages to aggregate output is from Gertler and Trigari (2009). At the firm level, we compute annual employment growth rate, its volatility and skewness as in Davis, Haltiwanger, Jarmin, and Miranda (2006) for the merged CRSP-Compustat sample for the period 1980-2012. Similarly, we determine the fraction of firms with no change in employment as emphasized by Cooper, Haltiwanger, and Willis (2007). We obtain the monthly series of the value-weighted market return and one-month Treasury bill from CRSP, and inflation from the Federal Reserve to compute the annualized first and second moments of the one-month real risk-free rate and real market return.

Overall, the model closely matches firm-level and aggregate employment quantities as well as financial market moments. In equilibrium, the aggregate unemployment rate is $5.8 \%$, the monthly aggregate hiring rate is $3.5 \%$, and the layoff rate is $1.3 \%$, close to what we observe

\footnotetext{
${ }^{16}$ The same intuition is shown to hold in general equilibrium for investment-specific shocks by Papanikolaou (2011).
} 
in the data. The model is also in with the average level of labor market tightness and its volatility. The labor share of income is $71 \%$ and the volatility of wages to output is $52 \%$, close to empirical estimates.

At the firm level, the model generates the observed high volatility in annual employment growth, $21.9 \%$ in the model relative to $21.6 \%$ in the data. Moreover, this volatility is coming from hiring and not firing, since the excess skewness of annual employment growth is positive and around 0.12 in both data and model. The proportional cost structure implies the existence of firms that are neither posting vacancies nor laying off workers. The percentage of CRSPCompustat firms with zero net annual employment growth rate is about $9.7 \%$. In the model, this fraction is $7.7 \%$. This finding lends support for the standard modeling assumption of proportional costs.

The pricing kernel and its calibration give rise to a realistic annual average market return $(8.8 \%)$ and volatility $(17.4 \%)$. In addition, the average risk-free rate is low (1\%) and smooth $(2 \%)$ as in the data.

\section{B. Equilibrium Forecasting Rules}

The goal of the model and calibration is to endogenously generate a negative relation between loadings on labor market tightness and expected returns, implying a negative factor risk premium of labor market tightness, $\lambda_{t}^{\theta}$. Given that aggregate productivity shocks carry a positive and efficiency shocks a negative price of risk, $\gamma_{x}>0$ and $\gamma_{p, 0}<0$, Proposition 1 (Equation (32) states that the model only generates a negative factor risk premium of labor market tightness if labor market tightness reacts positively to efficiency shocks, i.e., $\tau_{p}>0$.

The dynamics of labor market tightness (23) are the equilibrium outcome of firm policies and the solution to the labor market equilibrium condition $(22)$. In particular, the endogenous response of labor market tightness to efficiency shocks, $\tau_{p}>0$, depends on two economic forces, namely, a cash-flow and a discount rate effects, which work in opposite directions. To 
illustrate this trade-off, we compute the Euler equation for job creation, which is given by ${ }^{17}$

$$
\frac{\kappa_{h}}{q\left(\theta_{t}, p_{t}\right)}=\mathbb{E}_{t} M_{t+1}\left[e^{x_{t+1}+z_{i, t+1}} \alpha N_{i, t+1}^{\alpha-1}-w_{i, t+1}-N_{i, t+1} \frac{\partial w_{i, t+1}}{\partial N_{i, t+1}}+(1-s) \frac{\kappa_{h}}{q\left(\theta_{t+1}, p_{t+1}\right)}\right] .
$$

The left-hand side is the marginal cost and the right-hand the marginal benefit of job creation.

In Figure 3, we illustrate this trade-off by plotting labor market tightness as a function of matching efficiency. Consider a positive matching efficiency shock which shifts $p_{0}$ to $p_{1}$. A positive efficiency shock increases the rate at which vacancies are filled and thus reduces the marginal costs of hiring workers, i.e., the left-hand side of the Euler equation (36). This cash-flow effect implies that firms are willing to post more vacancies after a positive efficiency shock. Consequently, the equilibrium moves along the solid black line and shifts from point A to $\mathrm{B}$, resulting in a higher labor market tightness $\theta_{1}$. This effect causes a positive relation between labor market tightness and matching efficiency, i.e., $\tau_{p}>0$.

The cash-flow effect would be the only equilibrium effect in a setting in which agents are risk-neutral. Since we interested in the pricing of labor market risks, we assume that efficiency shocks carry a negative price of risk. As a result, a positive efficiency shock leads to an increase in discount rates. This discount rate effect implies that firms reduce vacancy postings, as an increase in discount rates reduces the value of job creation, i.e., the right-hand side of the Euler equation (36). In Figure 3, the discount rate effect shifts the equilibrium labor market tightness schedule downward. If the discount rate channel dominates the cash-flow channel (blue dotted line), then the new equilibrium is point $\mathrm{D}$, which is associated with a drop in labor market tightness to $\theta_{3}$ and thus $\tau_{p}<0$.

In line with the equity market data, our benchmark calibration implies that the cash-flow effect dominates the discount rate effect (dashed red line) such that labor market tightness is positively related with matching efficiency (point C in Figure 3). Quantitatively, the equilibrium labor market tightness dynamics are

$$
\log \theta_{t+1}=0.0043+0.9725 \log \theta_{t}+5.6190\left(x_{t+1}-\rho_{x} x_{t}\right)+0.1744\left(p_{t+1}-\rho_{p} p_{t}\right) .
$$

Labor market tightness is highly persistent and firms increase their vacancy postings after

\footnotetext{
${ }^{17}$ For simplicity, we ignore the Lagrange multipliers on vacancy postings $V_{i, t}$ and firing $F_{i, t}$.
} 
positive aggregate productivity shocks, $\tau_{x}>0$, and after positive efficiency shocks, $\tau_{p}>0$. Similarly, the equilibrium dynamics of (realized) market excess return are

$$
R_{M, t+1}^{e}=0.0080+0.8618\left(x_{t+1}-\rho_{x} x_{t}\right)-2.1741\left(p_{t+1}-\rho_{p} p_{t}\right)
$$

The average market excess return is 88 basis points per month and market prices increase after aggregate productivity shocks, $\nu_{x}>0$, and decrease after efficiency shocks, $\nu_{p}<0$, which is consistent with a positive price of risk for productivity shocks and a negative one for efficiency shocks.

These two dynamics allow us to compute stock return loadings on labor market tightness, which we will use in the following section to form portfolios. Proposition 1 (Equation (31) states the functional form for labor market tightness loadings, $\beta_{i, t}^{\theta}$. As the above discussion highlights, efficiency shocks and not productivity shocks are the driver of the labor market tightness premium. So to gain intuition behind Equation (31), we assume that loadings on the market are constant for simplicity. Labor market tightness loadings are negatively correlated with expected returns when $\nu_{x} /\left(\tau_{p} \nu_{x}-\tau_{x} \nu_{p}\right)>0$. Because productivity has a positive effect on job creation, $\tau_{x}>0$, and on market returns, $\nu_{x}>0$, this condition reduces to $\tau_{p}>\nu_{p}$ which again emphasizes that the cash-flow effect of efficiency shocks has to dominate the discount rate effect.

\section{Cross-Section of Returns}

In the previous section, we have shown that labor market tightness obtains a negative factor risk premium in equilibrium. To assess to what extent our model can quantitatively explain the empirically observed negative relation between loadings on labor market tightness and future stock returns, we follow the empirical procedure in Section II on simulated data. To this end, we sort the simulated panel of firms into decile portfolios according to their labor

market tightness loadings, $\beta_{i, t}^{\theta}$, as defined in Proposition 1. Table $\mathrm{X}$ compares the simulated return spread with the data on industry-neutral portfolios summarized in Table VII. As in the data, we form monthly value-weighted portfolios with annual rebalancing. The table reports average labor market tightness loadings, returns, and CAPM alphas across portfolios. 
The model generates a realistic dispersion in labor market tightness loadings across portfolios. The average monthly return difference between the low- and high-loading portfolios is $0.36 \%$ relative to $0.37 \%$ in the data. Moreover, the CAPM cannot explain the return differences across portfolios because in the model it does not span all systematic risk. In particular, Proposition 2 states that the CAPM alphas are inversely related with loadings on labor market tightness, as long as the market price of labor market tightness is negative.

The cash-flow channel of hiring costs impacts the cross-section of returns in the following way. Due to the proportional hiring and firing costs, the optimal firm policy exhibits regions of inactivity where firms neither hire nor fire workers. Figure 4 illustrates the optimal firm policy. The black line is the optimal policy when adjusting the workforce is costless. In the frictionless model, firms always adjust to the target employment size independent of the current size. The red curve is the optimal policy in the benchmark model. It displays two kinks. In the middle region where the optimal policy coincides with the 45 degree line, firms are inactive. In the inactivity region below the frictionless employment target, firms have too few workers but hiring is too costly. In the inactivity region above the frictionless employment target, firms have too many workers but firing is too costly.

Due to the time variation in matching efficiency, ideally, firms would like to hire when marginal hiring costs, $\kappa_{h} / q(\theta, p)$, are low. This holds for the majority of firms as vacancy postings increase with efficiency shocks. However, some firms are hit by low idiosyncratic productivity shocks such that hiring is not optimal when matching efficiency is high. For these firms, the employment policy is in the inaction region because the discount rate channel dominates the cash-flow channel. In addition, wages increase with labor market tightness, exacerbating low dividend payouts. Consequently, these firms have countercyclical dividends and valuations with respect to matching efficiency shocks, which renders them more risky. Since labor market tightness loadings and loadings on matching efficiency are positively related, our model can quantitatively replicate the negative relation between labor market tightness loadings and expected returns.

Selecting firms based on loadings on labor market conditions is informative about future 
returns whereas sorts based on hiring characteristics are not. In our model, the cost of hiring depends on labor market tightness but the employment growth rate characteristic does not control for this.

\section{Comparative Statics}

In Table XI, we compare the model-implied portfolio spreads from several alternative calibrations of the model to the baseline calibration in Table $\mathrm{X}$. We perform comparative statics over the model parameters or turn off different channels of the model to gain a better understanding of the modeling assumptions. As in the previous table, we form decile portfolios based on the labor market tightness loadings.

In the specifications of Model (1) and (2), we adjust the structure of the exogenous pricing kernel. In Model (1), we set $\gamma_{p, 0}=0$ so that the matching efficiency shocks are not priced. We raise the price of risk of the productivity shocks to 10 , i.e. $\gamma_{x}=10$, and keep all the other parameters equal to the baseline calibration so that the model-implied Sharpe ratio of the pricing kernel remains. With only the productivity shocks priced, the cross-sectional spread is small and negative -0.09 . This experiment shows that the priced variation in the aggregate matching efficiency is necessary for the labor market tightness factor to affect valuations.

The sensitivity parameter $\gamma_{p, 1}$ governs how the price of the matching efficiency risk varies over time. Specifically, $\gamma_{p, 1}$ being positive in the baseline calibration implies that the price of risk is greater in absolute terms when $\mathrm{p}$ shock is high. We set $\gamma_{p, 1}=0$ in Model (2) so that the aggregate matching efficiency shocks have constant price of risk. As a result, the simulated cross-sectional spread reduces from 0.36 to 0.22 , indicating the importance of the time variation in the price of risk of the matching efficiency shocks.

In Model (3) and (4), the matching efficiency shocks $p$ and the aggregate productivity shocks $x$ are turned off respectively so that Model (3) and (4) are each driven by aggregate productivity shocks and matching efficiency shocks, respectively. Since they are both one factor models, we do not compute the multivariate loadings as in Equation (3); rather, we calculate the univariate loadings on the labor market tightness alone. Consistent with the fact that labor market tightness is procyclical, in Model (3), LMT loads positively on aggregate 
productivity shocks and thus has a positive price of risk, failing to reproduce the observed portfolio spread. This analysis suggests that the negatively priced matching efficiency shocks are crucial to generate the correct negative relationship between LMT loadings and future portfolio returns. On the other hand, with only matching efficiency shocks in Model (4), labor market tightness has a negative price of risk. The portfolio spread exhibits the correct sign but a smaller magnitude compared to the data. This indicates the importance of modeling productivity shocks to generate enough cross-sectional heterogeneity among firms.

Model (5) to (9) analyze the importance of the labor search frictions by varying the parameters closely tied to the labor market. In Model (5), we break the dependency of the wage rate on the labor market equilibrium. We fix the $\theta_{t}$ term in the wage rate constant, equal to the average level of labor market tightness. As a result, the wage rate becomes less volatile, implying a stronger operating leverage effect. In the simulation, the model overshoots the data and generates a monthly portfolio spread of 0.44. In Model (6), we raise the bargaining power of workers to $\eta=0.5$ and adjust the mess of the labor force accordingly to match the unemployment rate of $5.8 \%$. As the wage rate becomes more cyclical, the simulated spread reduces to 0.18 . Both experiments indicate that the cyclical feature of the wage rate due to the wage bargaining process contributes to the pricing power of the LMT factor.

To understand to what extent wedges created by the search frictions drive the results, we set the firing cost $\kappa_{f}=0$ in Model (7) so that it is costless to downsize. The portfolio spread reduces to 0.31 , indicating that the frictions to downsize are not the major driving forces of the cross-sectional spread. In Model (8), we lower the unit vacancy posting cost $\kappa_{h}$ from 0.4 to 0.3 and adjust the size of the labor force to match the unemployment rate. The spread declines from 0.36 to 0.32 . This analysis shows that it is the cost of hiring rather than firing the major driving force of the cross-sectional spread.

In the baseline calibration, we set the fixed operating cost $f_{0}$ to match the corporate profit margin in the data. To examine the operating leverage effect generated from the fixed operating costs, we set $f_{0}=0$ in Model (9). The model simulated profit-output ratio becomes 0.22 , which is twice as large as in the data. As a result, the cross-sectional spread drops to 
0.15. This experiment shows that matching the profit margin from model to data is important to replicate the observed cross-sectional portfolio spread.

\section{Conclusion}

This paper analyzes the cross-sectional asset-pricing implications of a risk factor originating in the labor market. We first empirically document a robust negative relation between stock return loadings on changes in labor market tightness and future equity returns in the cross-section. We then develop a Labor Capital Asset Pricing Model with heterogeneous firms making dynamic employment decisions under labor search frictions which replicates the empirical facts.

We add two novel features to the standard labor search model. First, equilibrium labor market tightness is determined endogenously as the total number of optimal vacancies posted relative to the number of unemployed workers and depends on the time-varying firm-level distribution. Second, we assume that the efficiency of the matching technology is stochastic. As an equilibrium outcome, labor market tightness is positively related with efficiency shocks. Consequently, firms with low labor market tightness loadings are very sensitive to labor market

conditions that originate from matching efficiency shocks. These firms have cash flows which are not hedged against positive efficiency shocks and hence require a high expected stock returns. 


\section{Appendix}

\section{A. Data}

We describe the definitions of control variables in the Fama-MacBeth regressions of section IIE. The regressions use stock returns from July of year $t$ to June of year $t+1$ as dependent variables. We also provide definitions for firm characteristics studied in section II. Compustat data items are listed in parentheses where appropriate.

ME is the natural logarithm of market equity of the firm, calculated as the product of its price per share and number shares outstanding at the end of June of calendar year $t$.

$\mathrm{BM}$ is the natural logarithm of the ratio of book equity to market equity for the fiscal year ending in calendar year $t-1$. Book equity is defined following Davis, Fama, and French (2000) as stockholders' book equity (SEQ) plus balance sheet deferred taxes (TXDB) plus investment tax credit (ITCB) less the redemption value of preferred stock (PSTKRV). If the redemption value of preferred stock is not available, we use its liquidation value (PSTKL). If the stockholders' equity value is not available in Compustat, we compute it as the sum of the book value of common equity (CEQ) and the value of preferred stock. Finally, if these items are not available, stockholders' equity is measured as the difference between total assets (AT) and total liabilities (LT). Market equity used to compute the book-to-market ratio is the product of the price and the number of shares outstanding at the end of December of calendar year $t-1$.

$\mathrm{RU}$ is the stock return runup over twelve months ending in June of year $t$.

$\mathrm{HN}$ is the hiring rate, calculated following Belo, Lin, and Bazdresch (2013) as $\left(N_{t-1}-\right.$ $\left.N_{t-2}\right) /\left(\left(N_{t-1}+N_{t-2}\right) / 2\right)$, where $N_{t}$ is then number of employees (EMP) at the end of the fiscal year ending in calendar year $t$.

AG is the asset growth rate, calculated following Cooper, Gulen, and Schill (2008) as $A_{t-1} / A_{t-2}-1$, where $A_{t}$ is then value of total assets (AT) at the end of the fiscal year ending in calendar year $t$.

IK is the investment rate, calculated following Belo, Lin, and Bazdresch (2013) as the ratio of capital expenditure (CAPX) during the fiscal year ending in calendar year $t-1$ divided by 
fiscal year $t-2$ capital stock (PPENT).

Cash Flow 1 is defined following Cooper, Gulen, and Schill (2008) as [operating income before depreciation (OIBDP) - interest expenses (XINT) - taxes (TXT) - preferred dividends (DVP) - common dividends (DVC)] / total assets (AT).

Cash Flow 2 is defined by modifying Cooper, Gulen, and Schill (2008) definition to exclude dividends: [operating income before depreciation (OIBDP) - interest expenses (XINT) - taxes $(\mathrm{TXT})] /$ total assets (AT).

Return on assets is defined following Cooper, Gulen, and Schill (2008) as operating income before depreciation (OIBDP) scaled by total assets (AT).

\section{B. Wages}

In this section, we derive the Nash bargaining wage equation, in the spirit of Stole and Zwiebel (1996) and Kuehn, Petrosky-Nadeau, and Zhang (2012). Denote $S_{V_{i, t}}$ the marginal value of

a vacancy posting for a firm that posts positive vacancies. Let $\frac{\partial S_{i, t}^{H}}{\partial N_{i, t}}, \frac{\partial S_{i, t}^{I}}{\partial N_{i, t}}$, and $\frac{\partial S_{i, t}^{F}}{\partial N_{i, t}}$ be respectively the marginal values of an incumbent worker to a hiring firm, an inaction firm, and a firing firm. For a hiring firm, take the first order condition with respect to $N_{i, t+1}$, and apply the free entry conditions $S_{V_{i, t}}=0$, we obtain

$$
\frac{\partial S_{i, t}}{\partial V_{i, t}}=-\frac{\kappa_{h}}{q\left(\theta_{t}, p_{t}\right)}+\mathbb{E}_{t}\left[M_{t+1} S_{N_{i, t+1}}^{H}\right]=0
$$

We consider a stable outcome profile characterized in Stole and Zwiebel (1996). If the marginal worker leaves, the firm immediately loses the marginal product net of her wage payment. In addition, a wage renegotiation ensues with the remaining employee, which leads to a change in wage payment. In other words, the firm not only benefits from hiring the marginal worker through an increase in output by the marginal product of labor, but also an adjustment in the wage payment to all the existing workers. That is

$$
\frac{\partial S_{i, t}}{\partial N_{i, t}}=\frac{\partial Y_{i, t}}{\partial N_{i, t}}-w_{i, t}-\frac{\partial w_{i, t}}{\partial N_{i, t}} N_{i, t}+(1-s) \mathbb{E}_{t}\left[M_{t+1} S_{N_{i, t+1}}\right]
$$

where $S_{N_{i, t+1}}$ denote the marginal value of an incumbent worker at time $t+1$. 
In order to perform Nash bargaining over the total surplus of a match, we need to specify the marginal utilities to an employed and an unemployed worker. Since we do not model the household size, let us assume a hypothetical representative family that makes decisions on the extensive margin. $\phi_{t}$ is the marginal utility of the family that transforms money benefit to utils. Denote $J_{N_{i, t}}$ the marginal utility of an employed worker to the representative family, and $J_{V_{i, t}}$ the marginal value of an unemployed worker to the family. An unemployed worker receives the unemployment benefit $b$ for the current period. She has a probability $f\left(\theta_{t}\right)$ of finding a job at a hiring firm next period. We can write the following recursive form for $J_{U_{i, t}}$

$$
\frac{J_{U_{i, t}}}{\phi_{t}}=b+\mathbb{E}_{t}\left[M_{t+1}\left(f\left(\theta_{t}\right) \frac{J_{N_{i, t+1}}^{H}}{\phi_{t+1}}+\left(1-f\left(\theta_{t}\right)\right) \frac{J_{U_{i, t+1}}}{\phi_{t+1}}\right)\right] .
$$

Given workers' bargaining power $\eta$, Nash bargaining at time $t+1$ between the newly matched worker and the hiring firm satisfies the following

$$
\frac{J_{N_{i, t+1}}-J_{U_{i, t+1}}}{\phi_{t+1}}=\eta\left[\frac{J_{N_{i, t+1}}-J_{U_{i, t+1}}}{\phi_{t+1}}+S_{N_{i, t+1}}^{H}-S_{V_{i, t+1}}\right] .
$$

Combine 40, with (37), and plug in 39), we have

$$
\frac{J_{U_{i, t}}}{\phi_{t}}=b+\mathbb{E}\left[M_{t+1} \frac{J_{U_{i, t+1}}}{\phi_{t+1}}\right]+f\left(\theta_{t}\right) \frac{\eta}{1-\eta} \frac{\kappa_{h}}{q\left(\theta_{t}, p_{t}\right)} .
$$

An employed worker receives $w_{i, t}$ for period $t$, and has probability $s$ of quitting the job next period. We can write $J_{N_{i, t}}$ recursively

$$
\begin{aligned}
\frac{J_{N_{i, t}}}{\phi_{t}} & =w_{i, t}+\mathbb{E}_{t}\left[M_{t+1}\left((1-s) \frac{J_{N_{i, t+1}}}{\phi_{t+1}}+s \frac{J_{U_{i, t+1}}}{\phi_{t+1}}\right)\right] \\
& =w_{i, t}+\mathbb{E}_{t}\left[M_{t+1} \frac{J_{U_{i, t+1}}}{\phi_{t+1}}\right]+\frac{\eta}{1-\eta}(1-s) \mathbb{E}_{t}\left[M_{t+1} S_{N_{i, t+1}}\right] .
\end{aligned}
$$

The last step follows from Nash bargaining at time $t+1$ between the remaining worker and her firm, which is potentially hiring, firing or neither of the two.

Plug (38), 411), 42) into $\frac{J_{N_{i, t}}-J_{U_{i, t}}}{\phi_{t}}=\frac{\eta}{1-\eta}\left[S_{N_{i, t}}-S_{V_{i, t}}\right]$, and notice $\theta_{t}=\frac{f\left(\theta_{t}\right)}{q\left(\theta_{t}, p_{t}\right)}$. We conclude that the wage rate $w_{i, t}$ must satisfy the differential equation

$$
w_{i, t}-b=\eta\left[\frac{\partial Y_{i, t}}{\partial N_{i, t}}-\frac{\partial w_{i, t}}{\partial N_{i, t}} N_{i, t}+\kappa_{h} \theta_{t}\right]+(1-\eta) b .
$$

The wage rate is solved as

$$
w_{i, t}=\eta\left[\frac{\alpha}{1-\eta(1-\alpha)} \frac{Y_{i, t}}{N_{i, t}}+\kappa_{h} \theta_{t}\right]+(1-\eta) b
$$




\section{The Labor CAPM}

Proof of Proposition 1: A log-linear approximation of a pricing kernel is given by

$$
\frac{M_{t+1}}{\mathbb{E}_{t} M_{t+1}}=e^{m_{t+1}-\ln \left(\mathbb{E}_{t} M_{t+1}\right)} \approx 1+m_{t+1}-\ln \left(\mathbb{E}_{t} M_{t+1}\right) .
$$

Given the Euler equation $\mathbb{E}_{t}\left[M_{t+1} R_{t+1}^{e}\right]=0$, this implies

$$
\mathbb{E}_{t}\left[R_{i, t+1}^{e}\right]=-\operatorname{Cov}_{t}\left(m_{t+1}, R_{t+1}^{e}\right)
$$

For the pricing kernel (17), this implies

$$
\begin{aligned}
\mathbb{E}_{t}\left[R_{i, t+1}^{e}\right] & =\gamma_{x} \operatorname{Cov}_{t}\left(x_{t+1}, R_{i, t+1}^{e}\right)+\gamma_{p} \operatorname{Cov}_{t}\left(p_{t+1}, R_{i, t+1}^{e}\right) \\
& =\beta_{i, t}^{x} \lambda^{x}+\beta_{i, t}^{p} \lambda_{t}^{p}
\end{aligned}
$$

where risk loadings are given by

$$
\beta_{i, t}^{x}=\frac{\operatorname{Cov}_{t}\left(x_{t+1}, R_{i, t+1}^{e}\right)}{\sigma_{x}^{2}} \quad \beta_{i, t}^{p}=\frac{\operatorname{Cov}_{t}\left(p_{t+1}, R_{i, t+1}^{e}\right)}{\sigma_{p}^{2}},
$$

and factor risk premia are

$$
\lambda^{x}=\gamma_{x} \sigma_{x}^{2} \quad \lambda_{t}^{p}=\gamma_{p, t} \sigma_{p}^{2}
$$

Given the pricing kernel (27) and laws of motions (24) and (26), it follows from (45) that

$$
\mathbb{E}_{t}\left[R_{i, t+1}^{e}\right]=\left(\gamma_{M, t} \nu_{x}+\gamma_{\theta, t} \tau_{x}\right) \operatorname{Cov}_{t}\left(x_{t+1}, R_{i, t+1}^{e}\right)+\left(\gamma_{\theta, t} \tau_{p}+\gamma_{M, t} \nu_{p}\right) \operatorname{Cov}_{t}\left(p_{t+1}, R_{i, t+1}^{e}\right) .
$$

Thus, by matching coefficients in terms of covariance of (46) and 48, it follows that

$$
\gamma_{x}=\gamma_{M, t} \nu_{x}+\gamma_{\theta, t} \tau_{x} \quad \gamma_{p, t}=\gamma_{\theta, t} \tau_{p}+\gamma_{M, t} \nu_{p}
$$

implying (28) holds.

Since $x_{t}$ and $p_{t}$ are uncorrelated, the factor loadings $\beta^{x}$ and $\beta^{p}$ satisfy the regression

$$
R_{i, t+1}^{e}-\mathbb{E}_{t}\left[R_{i, t+1}^{e}\right]=\beta_{i, t}^{x}\left(x_{t+1}-\rho_{x} x_{t}\right)+\beta_{i, t}^{p}\left(p_{t+1}-\rho_{p} p_{t}\right)+\epsilon_{i, t+1},
$$

with loadings defined in equation (48). Similarly, the loadings on the market return and labor market tightness satisfy the regression

$$
R_{i, t+1}^{e}-\mathbb{E}_{t}\left[R_{i, t+1}^{e}\right]=\beta_{i, t}^{M}\left(R_{M, t+1}^{e}-\mathbb{E}_{t}\left[R_{M, t+1}^{e}\right]\right)+\beta_{i, t}^{\theta}\left(\vartheta_{t+1}-\mathbb{E}_{t}\left[\vartheta_{t+1}\right]\right)+\epsilon_{i, t+1}
$$


Notice that since $R_{M, t+1}^{e}$ and $\vartheta_{t+1}$ are not independent, it follows that

$$
\beta_{i, t}^{M} \neq \frac{\operatorname{Cov}_{t}\left(R_{i, t+1}^{e}, R_{M, t+1}^{e}\right)}{\operatorname{Var}_{t}\left(R_{M, t+1}^{e}\right)} \quad \beta_{i, t}^{\theta} \neq \frac{\operatorname{Cov}_{t}\left(R_{i, t+1}^{e}, \vartheta_{t+1}\right)}{\operatorname{Var}_{t}\left(\vartheta_{t+1}\right)}
$$

To compute the loadings on the market return and labor market tightness, equate equations (51) and (52) and substitute in laws of motion (24) and (26), thus,

$$
\begin{aligned}
& \beta_{i, t}^{x}\left(x_{t+1}-\rho_{x} x_{t}\right)+\beta_{i, t}^{p}\left(p_{t+1}-\rho_{p} p_{t}\right)+\epsilon_{i, t+1}= \\
& \beta_{i, t}^{M}\left(\nu_{x}\left(x_{t+1}-\rho_{x} x_{t}\right)+\nu_{p}\left(p_{t+1}-\rho_{p} p_{t}\right)\right)+\beta_{i, t}^{\theta}\left(\tau_{x}\left(x_{t+1}-\rho_{x} x_{t}\right)+\tau_{p}\left(p_{t+1}-\rho_{p} p_{t}\right)\right)+\epsilon_{i, t+1} .
\end{aligned}
$$

By matching the coefficients in terms of $\left(x_{t+1}-\rho_{x} x_{t}\right)$ and $\left(p_{t+1}-\rho_{p} p_{t}\right)$, we get

$$
\beta_{i, t}^{x}=\beta_{i, t}^{M} \nu_{x}+\beta_{i, t}^{\theta} \tau_{x} \quad \beta_{i, t}^{p}=\beta_{i, t}^{M} \nu_{p}+\beta_{i, t}^{\theta} \tau_{p}
$$

implying that (30) and (31) hold.

Next, substitute (30) and (31) into (29)

$$
\mathbb{E}_{t}\left[R_{i, t+1}^{e}\right]=\frac{\tau_{x} \beta_{i, t}^{p}-\tau_{p} \beta_{i, t}^{x}}{\nu_{p} \tau_{x}-\nu_{x} \tau_{p}} \lambda_{t}^{M}+\frac{\nu_{p} \beta_{i, t}^{x}-\nu_{x} \beta_{i, t}^{p}}{\nu_{p} \tau_{x}-\nu_{x} \tau_{p}} \lambda_{t}^{\theta}
$$

and matching the coefficients of $\beta_{i, t}^{x}$ and $\beta_{i, t}^{p}$ with 47) implies

$$
\begin{aligned}
& \lambda^{x}\left(\nu_{p} \tau_{x}-\nu_{x} \tau_{p}\right)=\nu_{p} \lambda_{t}^{\theta}-\tau_{p} \lambda_{t}^{M} \\
& \lambda_{t}^{p}\left(\nu_{p} \tau_{x}-\nu_{x} \tau_{p}\right)=\tau_{x} \lambda_{t}^{M}-\nu_{x} \lambda_{t}^{\theta}
\end{aligned}
$$

Solving for $\lambda_{t}^{\theta}$ and $\lambda_{t}^{M}$ confirms (32).

Proof of Proposition 2: Given (26), univariate loadings on the market return can be computed via

$$
\begin{aligned}
\beta_{i, t}^{C A P M} & =\frac{\operatorname{Cov}_{t}\left(R_{i, t+1}^{e}, R_{M, t+1}^{e}\right)}{\operatorname{Var}_{t}\left(R_{M, t+1}^{e}\right)} \\
& =\frac{\nu_{x} \operatorname{Cov}_{t}\left(R_{i, t+1}^{e}, x_{t+1}\right)+\nu_{p} \operatorname{Cov}_{t}\left(R_{i, t+1}^{e}, p_{t+1}\right)}{\operatorname{Var}_{t}\left(R_{M, t+1}^{e}\right)}=\frac{\nu_{x} \sigma_{x}^{2} \beta_{i, t}^{x}+\nu_{p} \sigma_{p}^{2} \beta_{i, t}^{p}}{\nu_{x}^{2} \sigma_{x}^{2}+\nu_{p}^{2} \sigma_{p}^{2}} .
\end{aligned}
$$

Notice that the CAPM factor risk premium stays the same in the factor or multi-factor models, that is, $\lambda_{t}^{C A P M}=\lambda_{t}^{M}=\nu_{x} \lambda^{x}+\nu_{p} \lambda_{t}^{p}$. Given the pricing of expected excess returns in 
terms of independent aggregate risks, $\mathbb{E}_{t}\left[R_{i, t+1}^{e}\right]=\beta_{i, t}^{x} \lambda_{t}^{x}+\beta_{i, t}^{p} \lambda_{t}^{p}$, we can calculate the CAPM mispricing as

$$
\alpha_{i, t}^{C A P M}=\beta_{i, t}^{x} \lambda_{t}^{x}+\beta_{i, t}^{p} \lambda_{t}^{p}-\beta_{i, t}^{C A P M} \lambda_{t}^{C A P M}=\frac{\left(\beta_{i, t}^{x} \nu_{p}-\beta_{i, t}^{p} \nu_{x}\right)\left(\nu_{p} \gamma_{x}-\nu_{x} \gamma_{p}\right) \sigma_{x}^{2} \sigma_{p}^{2}}{\nu_{x}^{2} \sigma_{x}^{2}+\nu_{p}^{2} \sigma_{p}^{2}} .
$$

Using the definition of $\beta_{i, t}^{\theta}$ in (31) and $\gamma_{\theta, t}$ in (28), it follows that (34) holds.

\section{Computational Algorithm}

To solve the model numerically, we discretize the state space. All shocks $(x, z, p)$ follow finite states Markov chains according to Rouwenhorst (1995) with 5 states for $x, 11$ for $z$ and 5 for $p$. We create an evenly spaced grid of 50 points for employment $N$ in the interval $[0.01,5.0]$. The lower and upper bounds of $N$ are set such that the optimal policies are not binding in the simulation $^{18}$. The space of the labor market tightness $\theta$ needs to be transformed into a discrete space as well. We use an evenly spaced grid in the interval $[0.25,1.25]$ with 30 points. The upper bound for $\theta$ is chosen such that the simulated paths of equilibrium labor market tightness never step outside the bounds. The choice variable $N^{\prime}$ is a vector containing 5000 elements evenly spaced on the interval $[0.01,5.0]$. We use linear interpolation to obtain the value function off grid points. Our results are robust to a higher numbers of the grid points, non-evenly spaced grids, and nonlinear interpolation methods.

The computation algorithm amounts to the following iterative procedure:

1. Initial guess: Take an initial guess for the coefficient vector $\tau$ in the law of motion (23). Since the time series of $\theta_{t}$ is procyclical and highly persistent, we start from $\tau=(-0.23 ; 0.5 ; 0 ; 0 ; 1 ; 0)$. At steady state, $\tau_{0}=\left(1-\tau_{\theta}\right) \log \theta^{s s}=-0.23$.

2. Optimization: Solve the firm's optimization problem (19) given the forecasting rule coefficients $\tau$. For this step we use value function iteration. Specifically, the firm value function solves

$$
S(N, z, x, p, \theta)=\max \left\{S(N, z, x, p, \theta)^{h}, S(N, z, x, p, \theta)^{f}\right\}
$$

\footnotetext{
${ }^{18}$ In this heterogeneous firms model, as long as the aggregate employment rate is well-defined in [0,1], individual firm size is not bounded by 1 as in the case of representative firm models.
} 
where

$$
\begin{aligned}
S(N, z, x, p, \theta)^{h}= & \max _{N^{\prime} \geq(1-s) N}\left\{(1-\eta) e^{x+z} N^{\alpha}-\left[\eta \kappa_{h} \theta+(1-\eta) b\right] N-\right. \\
& \left.\frac{\kappa_{h}}{q(\theta)}\left[N^{\prime}-(1-s) N\right]+\mathbb{E}\left[M^{\prime} S\left(N^{\prime}, z^{\prime}, x^{\prime}, p^{\prime}, \theta^{\prime}\right) \mid z, N, x, p, \theta\right]\right\},
\end{aligned}
$$

and

$$
\begin{aligned}
S(N, z, x, p, \theta)^{f}= & \max _{N^{\prime} \leq(1-s) N}\left\{(1-\eta) e^{x+z} N^{\alpha}-\left[\eta \kappa_{h} \theta+(1-\eta) b\right] N-\right. \\
& \left.\kappa_{f}\left[(1-) N-N^{\prime}\right]+\mathbb{E}\left[M^{\prime} S\left(N^{\prime}, z^{\prime}, x^{\prime}, p^{\prime}, \theta^{\prime}\right) \mid z, N, x, p, \theta\right]\right\} .
\end{aligned}
$$

3. Simulation: Use the firm's optimal employment policies $V(N, z, x, p, \theta)$ and $F(N, z, x, p, \theta)$ to simulate a panel of $N=5000$ firms over $T=5300$ periods. Here we emphasize that at each period, we impose labor market equilibrium by solving $\theta_{t}$ as the fixed point in Equation (22). In this fashion, we obtain a time series of realized $\theta_{t}$.

4. Update coefficients: we truncate the initial 300 months as burn-in periods, and use the stationary region of the simulated data to estimate the vector $\tau$ by OLS. Update the forecasting coefficients, and restart from the optimization step. Continue the outer loop iteration until the coefficients converge and the goodness-of-fit measures are satisfactory. 


\section{References}

Andolfatto, David, 1996, Business cycles and labor-market search, American Economic Review 86, $112-32$.

Asness, Clifford S., R. Burt, Porter Ross, and L. Stevens, 2000, Predicting stock returns using industryrelative firm characteristics, Working paper.

Barnichon, Regis, 2010, Building a composite help-wanted index, Economics Letters 109, 175-178.

, and Andrew Figura, 2011, Labor market heterogeneities and the aggregate matching function, Working paper.

Beauchemin, Kenneth, and Murat Tasci, 2012, Diagnosing labor market search models: a multipleshock approach, Macroeconomic Dynamics forthcoming.

Belo, Frederico, Xiaoji Lin, and Santiago Bazdresch, 2013, Labor hiring, investment, and stock return predictability in the cross section, Journal of Political Economy Forthcoming.

Berk, Jonathan, Richard C. Green, and Vasant Naik, 1999, Optimal investment, growth options, and security returns, Journal of Finance 54, 1553-1607.

Boguth, Oliver, Murray Carlson, Adlai Fisher, and Mikhail Simutin, 2011, Conditional risk and performance evaluation: Volatility timing, overconditioning, and new estimates of momentum alphas, Journal of Financial Economics 102, 363-389.

Carhart, Mark M., 1997, On persistence in mutual fund performance, Journal of Finance 52, 57-82.

Carlson, Murray, Adlai Fisher, and Ron Giammarino, 2004, Corporate investment and asset price dynamics: Implications for the cross-section of returns, Journal of Finance 59, 2577-2603.

Chen, Huafeng Jason, Marcin Kacperczyk, and Hernn Ortiz-Molina, 2011, Labor unions, operating flexibility, and the cost of equity, Journal of Financial and Quantitative Analysis 46, 25-58.

Cheremukhin, Anton A., and Paulina Restrepo-Echavarria, 2010, The labor wedge as a matching friction, Working paper.

Cochrane, John H., 1991, Production-based asset pricing and the link between stock returns and economic-fluctuations, Journal of Finance 46, 209-237.

Cohen, Randolph B., and Christopher Polk, 1998, The impact of industry factors in asset-pricing tests, Working paper.

Cooper, Ilan, 2006, Asset pricing implications of non-convex adjustment costs of investment, Journal of Finance 61, 139-170.

Cooper, Michael J., Huseyin Gulen, and Michael S. Schill, 2008, Asset growth and the cross-section of stock returns, Journal of Finance 63, 1609-1651.

Cooper, Russell, John Haltiwanger, and Jonathan L. Willis, 2007, Search frictions: Matching aggregate and establishment observations, Journal of Monetary Economics 54, 56-78.

Danthine, Jean-Pierre, and John B. Donaldson, 2002, Labor relation and asset returns, Review of Economic Studies 69, 41-64.

Davis, James L., Eugene F. Fama, and Kenneth R. French, 2000, Characteristics, covariances, and average returns: 1929 to 1997, Journal of Finance 55, 389-406. 
Davis, Steven J., Jason R. Faberman, John C. Haltiwanger, and Ian Rucker, 2010, Adjusted estimates of worker flows and job openings in JOLTS, in Katharine G. Abraham, James R. Spletzer, and Michael J. Harper, ed.: Labor in the New Economy . pp. 187-216 (University of Chicago Press).

Davis, Steven J., R. Jason Faberman, and John Haltiwanger, 2006, The flow approach to labor markets: New data sources and micro-macro links, Journal of Economic Perspectives 20, 3-26.

Davis, Steven J., John Haltiwanger, Ron Jarmin, and Javier Miranda, 2006, Volatility and dispersion in business growth rates: Publicly traded versus privately held firms, NBER Macroeconomics Annual $21,107-179$.

den Haan, Wouter J., Garey Ramey, and Joel Watson, 2000, Job destruction and propagation of shocks, American Economic Review 90, 482-498.

Diamond, Peter A, 1982, Wage determination and efficiency in search equilibrium, Review of Economic Studies 49, 217-27.

Donangelo, Andres, 2012, Labor mobility: Implications for asset pricing, Journal of Finance forthcoming.

Eisfeldt, Andrea, and Dimitris Papanikolaou, 2013, Organization capital and the cross-section of expected returns, Journal of Finance 68, 1365-1406.

Elsby, Michael W. L., and Ryan Michaels, 2013, Marginal jobs, heterogeneous firms, and unemployment flows, American Economic Journal: Macroeconomics 5, 1-48.

Fama, Eugene F., and Kenneth R. French, 1992, The cross-section of expected stock returns, Journal of Finance 47, 427-465.

- 1993, Common risk-factors in the returns on stocks and bonds, Journal of Financial Economics $33,3-56$.

Fama, Eugene F., and James D. MacBeth, 1973, Risk, return, and equilibrium - empirical tests, Journal of Political Economy 81, 607-636.

Favilukis, Jack, and Xiaoji Lin, 2012, Wage rigidity: A solution to several asset pricing puzzles, Working Paper.

Ferson, Wayne E, and Rudi W Schadt, 1996, Measuring fund strategy and performance in changing economic conditions, Journal of Finance 51, 425-461.

Fujita, Shigeru, 2011, Effects of extended unemployment insurance benefits: evidence from the monthly CPS, Working paper.

— , and Makoto Nakajima, 2013, Worker flows and job flows: A quantitative investigation, FRB of Philadelphia Working paper.

Furlanetto, Francesco, and Nicolas Groshenny, 2012, Matching efficiency and business cycle fluctuations, CAMA Working paper.

Gertler, Mark, and Antonella Trigari, 2009, Unemployment fluctuations with staggered nash wage bargaining, Journal of Political Economy 117, 38-86.

Gomes, Joao, Leonid Kogan, and Lu Zhang, 2003, Equilibrium cross section of returns, Journal of Political Economy 111, 693-732.

Gomes, Joao F., and Lukas Schmid, 2010, Levered returns, Journal of Finance 65, 467-494. 
Gomme, Paul, and Peter Rupert, 2007, Theory, measurement and calibration of macroeconomic models, Journal of Monetary Economics 54, 460-497.

Gourio, François, 2007, Labor leverage, firms' heterogeneous sensitivities to the business cycle, and the cross-section of expected returns, Working paper.

Hagedorn, Marcus, and Iourii Manovskii, 2008, The cyclical behavior of equilibrium unemployment and vacancies revisited, American Economic Review 98, 1692-1706.

Hall, Robert E., 2005, Employment fluctuations with equilibrium wage stickiness, American Economic Review 95, 50-65.

- and Paul R. Milgrom, 2008, The limited influence of unemployment on the wage bargain, American Economic Review 98, 1653-74.

Herz, Benedikt, and Thijs van Rens, 2011, Accounting for mismatch unemployment, Working paper.

Jegadeesh, Narasimhan, and Sheridan Titman, 1993, Returns to buying winners and selling losers implications for stock-market efficiency, Journal of Finance 48, 65-91.

Jermann, Urban J., 1998, Asset pricing in production economies, Journal of Monetary Economics 41, $257-275$.

Kogan, Leonid, and Dimitris Papanikolaou, 2012, Growth opportunities, technology shocks, and asset prices, Journal of Finance Forthcoming.

— 2013, Firm characteristics and stock returns: The role of investment-specific shocks, Review of Financial Studies Forthcoming.

Krusell, Per, and Jr. Smith, Anthony A., 1998, Income and wealth heterogeneity in the macroeconomy, Journal of Political Economy 106, 867-96.

Kuehn, Lars-Alexander, Nicolas Petrosky-Nadeau, and Lu Zhang, 2012, An equilibrium asset pricing model with labor market search, NBER Working paper.

Lubik, Thomas A., 2009, Estimating a search and matching model of the aggregate labor market, Economic Quarterly pp. 101-120.

Merz, Monika, 1995, Search in the labor market and the real business cycle, Journal of Monetary Economics 36, 269-300.

_ and Eran Yashiv, 2007, Labor and the market value of the firm, American Economic Review 97, 1419-1431.

Mortensen, Dale T., 1982, The matching process as a noncooperative bargaining game, in The Economics of Information and Uncertainty . pp. 233-258 (NBER).

— 2010, Wage dispersion in the search and matching model, American Economic Review 100, $338-42$.

Mortensen, Dale T, and Christopher A Pissarides, 1994, Job creation and job destruction in the theory of unemployment, Review of Economic Studies 61, 397-415.

Newey, Whitney K., and Kenneth D. West, 1987, A simple, positive semidefinite, heteroskedasticity and autocorrelation consistent covariance-matrix, Econometrica 55, 703-708.

Novy-Marx, Robert, 2011, Operating leverage, Review of Finance 39, 103-134. 
Papanikolaou, Dimitris, 2011, Investment shocks and asset prices, Journal of Political Economy 119, 639-685.

Pissarides, Christopher A., 1985, Short-run equilibrium dynamics of unemployment, vacancies, and real wages, American Economic Review 75, 676-690.

, 2009, The unemployment volatility puzzle: Is wage stickiness the answer?, Econometrica 77, $1339-1369$.

— , 2011, Equilibrium in the labor market with search frictions, American Economic Review 101, $1092-1105$.

Sahin, Aysegul, Joseph Song, Giorgio Topa, and Giovanni L. Violante, 2012, Mismatch unemployment, NBER Working paper.

Shimer, Robert, 2005, The cyclical behavior of equilibrium unemployment and vacancies, American Economic Review 95, 25-49.

Simutin, Mikhail, 2010, Excess cash and stock returns, Financial Management 39, 1197-1222.

Sterk, Vincent, 2010, Home equity, mobility, and macroeconomic fluctuations, DNB Working paper.

Stole, Lars A., and Jeffrey Zwiebel, 1996, Intra-firm bargaining under non-binding contracts, Review of Economic Studies 63, 375-410.

Zhang, Lu, 2005, The value premium, Journal of Finance 60, 67-103. 


\section{A. Vacancy Index}
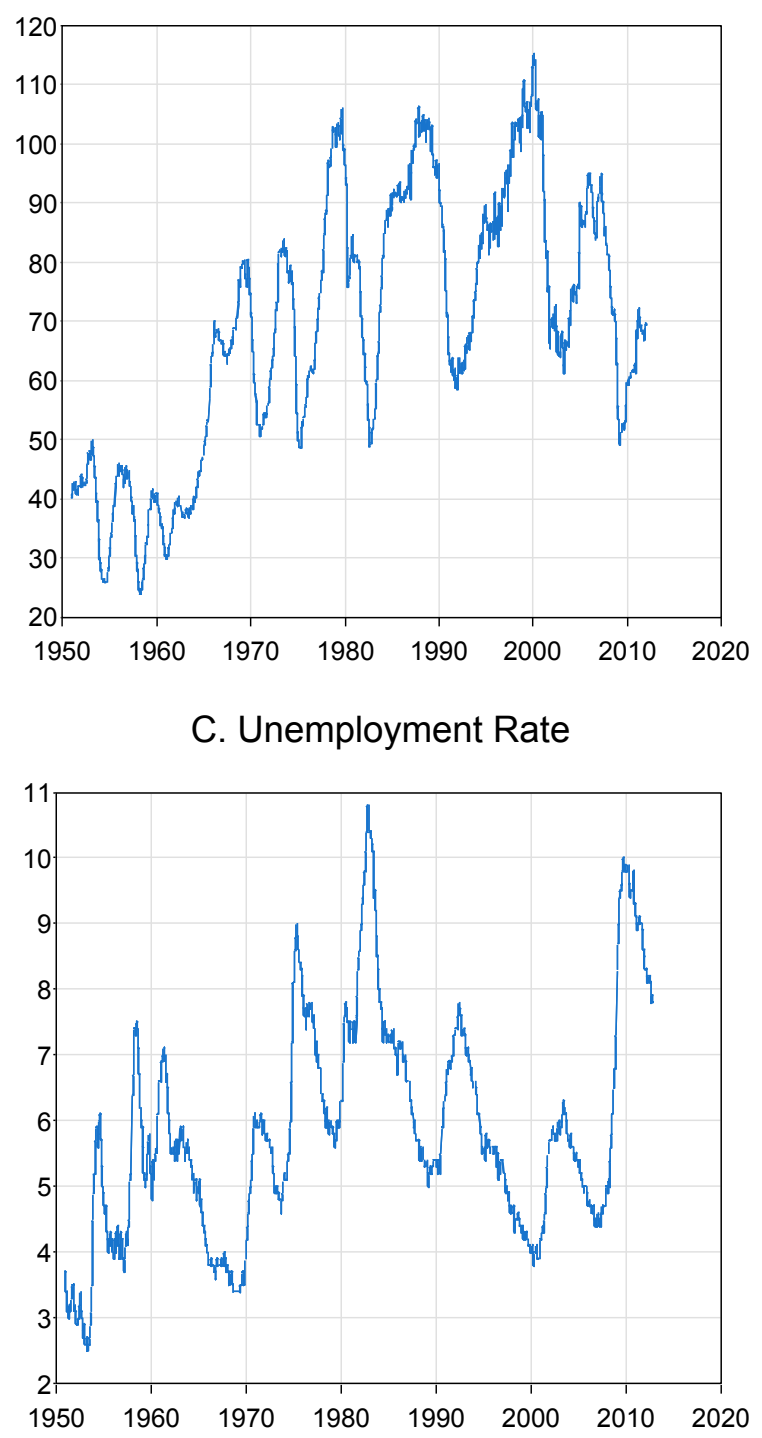

B. Labor Force Participation Rate
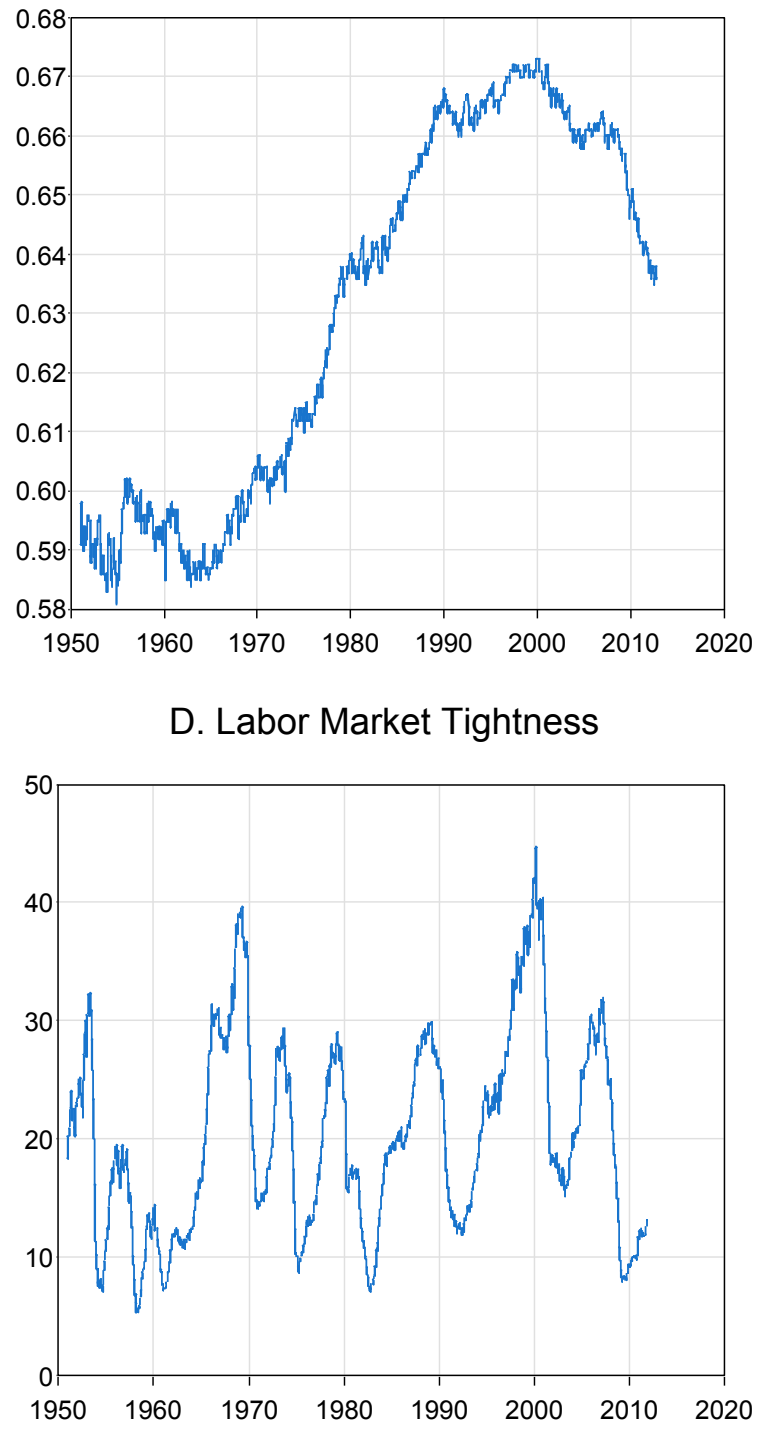

Figure 1. Labor Market Tightness and Its Components

This figure plots the monthly time series of the vacancy index, the labor force participation rate, the unemployment rate, and the labor market tightness. 


\section{A. Log Cumulative Return of the Low - High Portfolio}

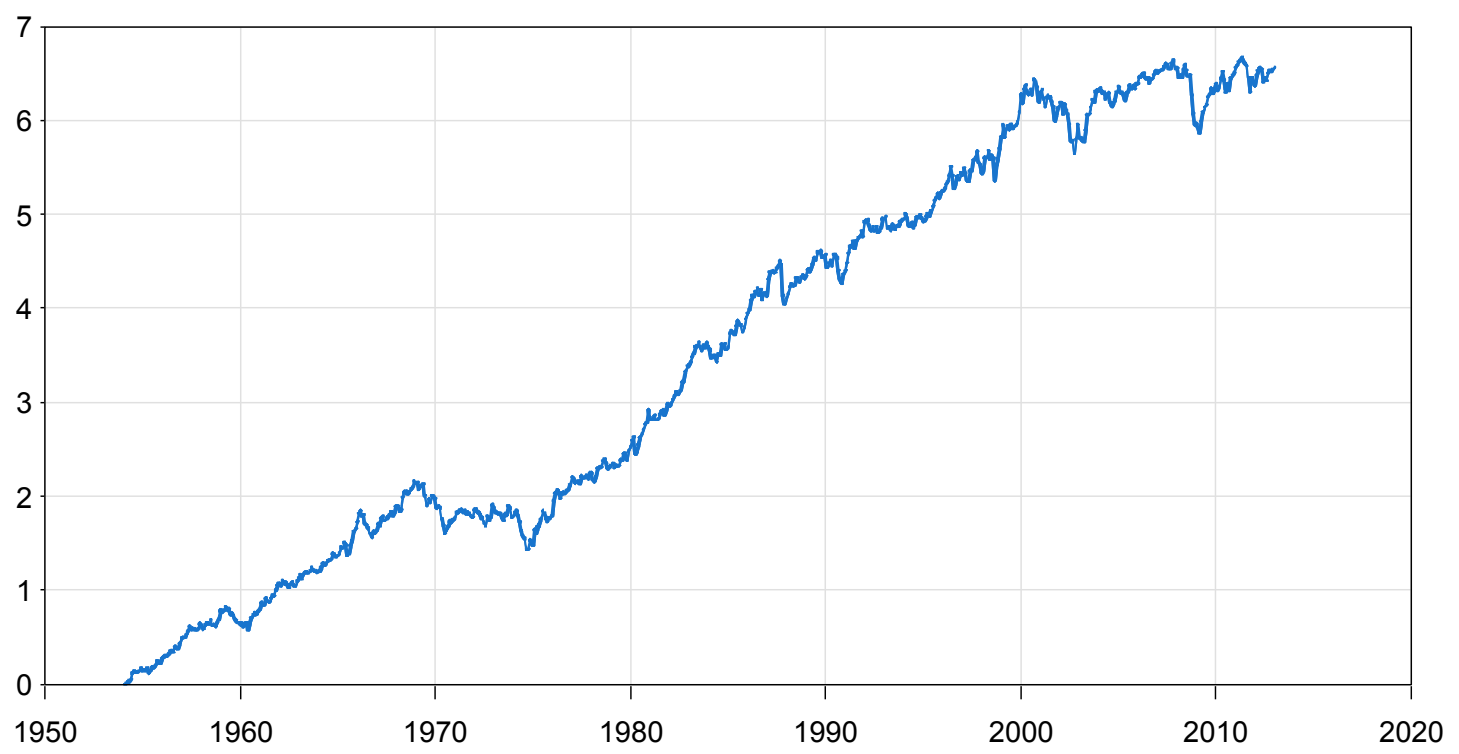

B. Monthly Return of the Low - High Portfolio

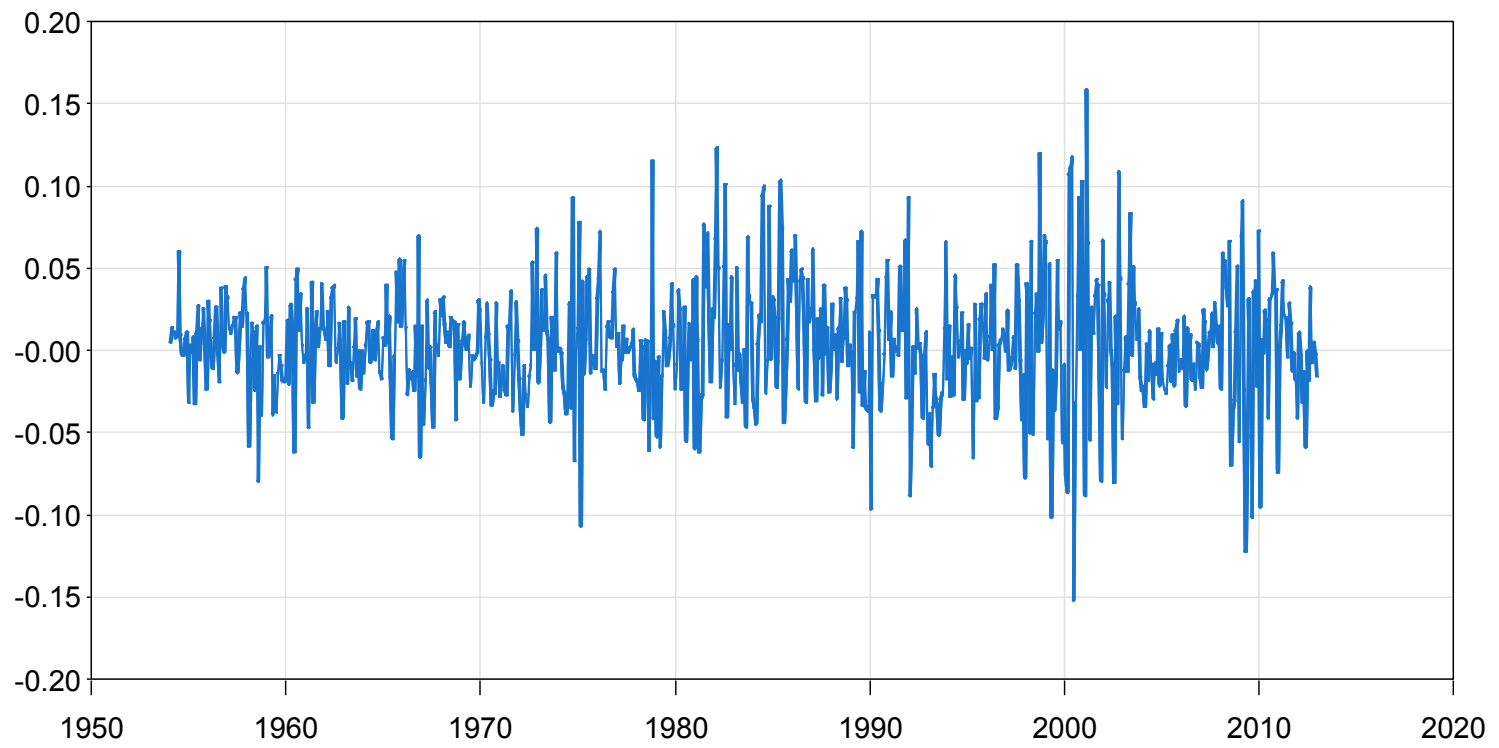

Figure 2. Returns of the Labor Market Tightness Factor

This figure plots in Panel A the log cumulative return of the portfolio that longs the decile of stocks with the lowest exposure to the labor market tightness factor and shorts the decile of stocks with the highest loadings and plots in Panel B the monthly returns of this portfolio. 


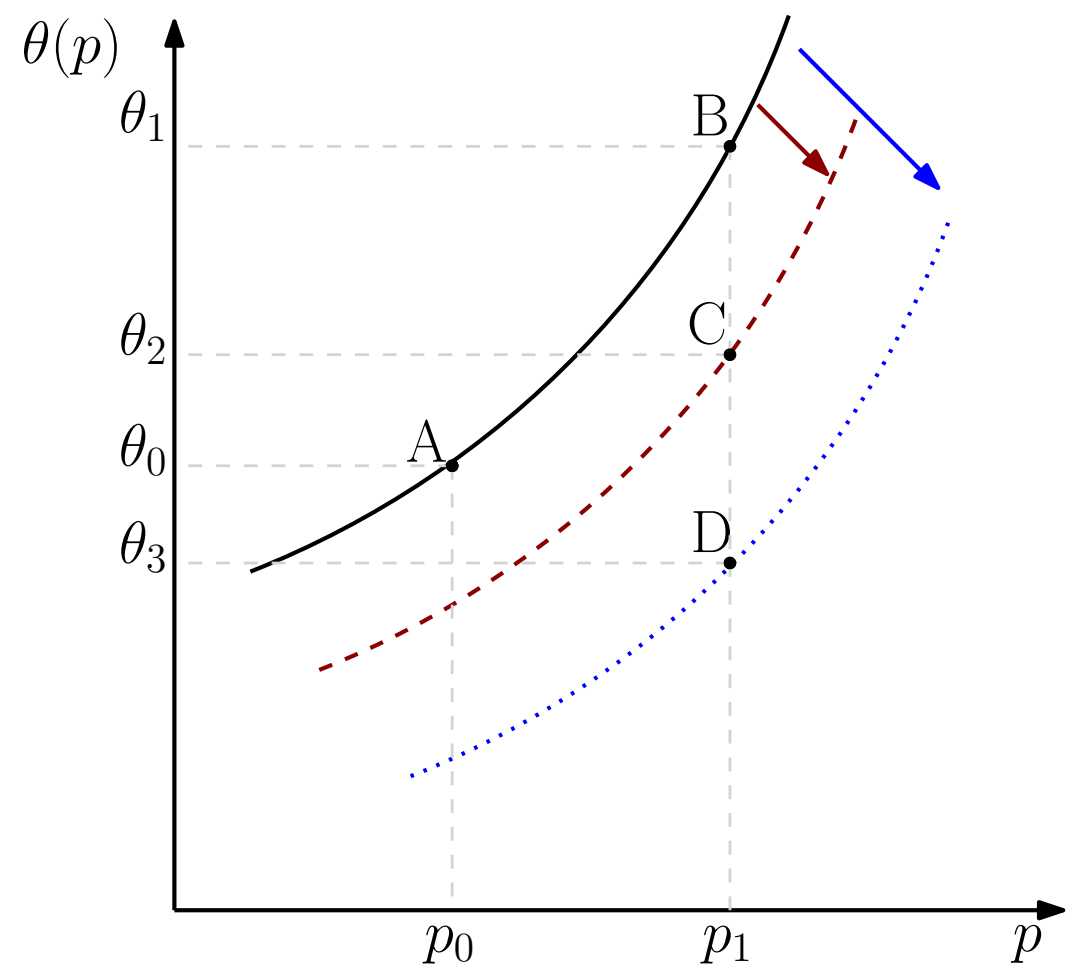

Figure 3. Labor Market Tightness and Efficiency Shock

This figure illustrates the endogenous relation between equilibrium labor market tightness, $\theta(p)$, and efficiency shocks, $p$, to the matching technology. 


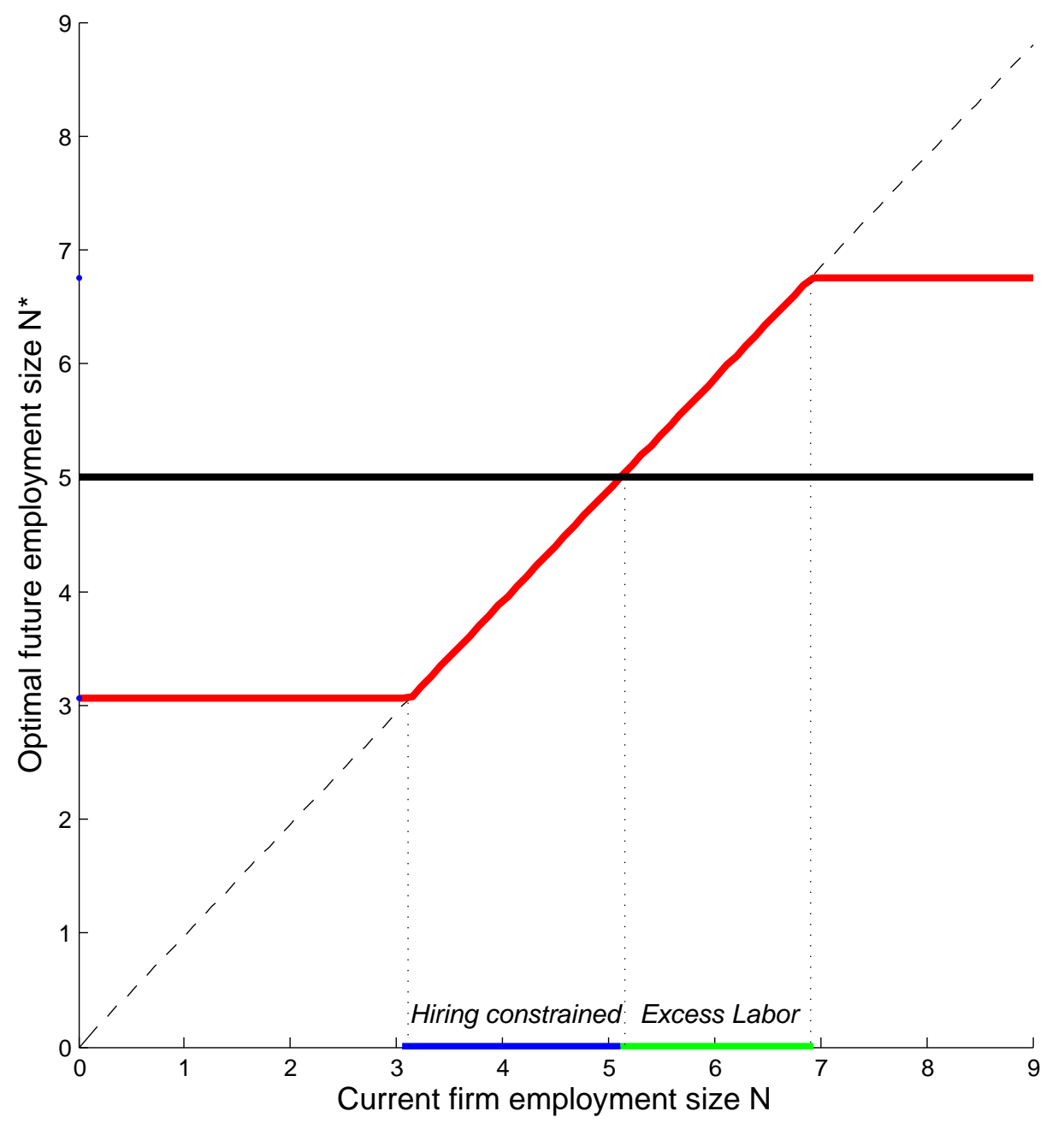

Figure 4. Optimal Employment Policies for a Firm under Search Frictions

This figure demonstrates the optimal labor adjustment policies for a firm under labor search frictions. The horizontal axis plots the firm's current employment level $N$, and the vertical axis indicates the optimal future employment level $N^{*}$, keeping firm's other state variables $(x, p, \theta, z)$ fixed. The black horizontal line indicates the optimal future employment level in a frictionless environment, which is independent of the current employment $N$. In contrast, the solid red curve $N^{*}$ depicts the optimal policies under search frictions. The region Hiring constraint denotes firms who wish to, but cannot refill their lost workers. The region Excess labor consists firms who wish to, but cannot discharge its workforce. The sum of the two regions are referred to as the Inaction region, in which firms do not adjust the employee size freely. 
Table I

Summary Statistics

This table reports summary statistics for the monthly labor market tightness factor $(\vartheta)$, change in the vacancy index (VAC), change in the unemployment rate (UNEMP), change in the labor force participation rate (LFPR), change in the industrial production (IP), change in the consumer price index (CPI), dividend yield (DY), T-bill rate (TB), term spread (TS), and default spread (DS) calculated for the 1954-2012 period. Means and standard deviations are in percent.

\begin{tabular}{|c|c|c|c|c|c|c|c|c|c|c|c|}
\hline & \multirow[b]{2}{*}{ Mean } & \multirow[b]{2}{*}{ St dev } & \multicolumn{9}{|c|}{ Correlations } \\
\hline & & & $\vartheta$ & VAC & UNEMP & LFPR & IP & CPI & DY & $\mathrm{TB}$ & TS \\
\hline$\vartheta$ & 0.02 & 5.48 & & & & & & & & & \\
\hline VAC & -0.10 & 3.46 & 0.78 & & & & & & & & \\
\hline UNEMP & 0.16 & 3.38 & -0.83 & -0.36 & & & & & & & \\
\hline LFPR & 0.01 & 0.30 & -0.13 & 0.04 & 0.15 & & & & & & \\
\hline IP & 0.24 & 0.89 & 0.56 & 0.44 & -0.48 & 0.04 & & & & & \\
\hline CPI & 0.31 & 0.32 & -0.08 & -0.04 & 0.06 & 0.05 & -0.08 & & & & \\
\hline DY & 3.20 & 1.13 & -0.14 & 0.00 & 0.12 & 0.07 & -0.10 & 0.34 & & & \\
\hline TB & 0.39 & 0.24 & -0.12 & -0.08 & 0.04 & 0.05 & -0.09 & 0.52 & 0.51 & & \\
\hline TS & 1.45 & 1.22 & 0.11 & 0.10 & -0.05 & -0.03 & 0.04 & -0.29 & -0.12 & -0.39 & \\
\hline DS & 0.99 & 0.45 & -0.26 & -0.20 & 0.22 & -0.03 & -0.28 & 0.11 & 0.33 & 0.33 & 0.29 \\
\hline
\end{tabular}




\section{Table II}

\section{Characteristics of Labor Market Tightness Portfolios}

This table reports average characteristics for the ten portfolios of stocks sorted by their loadings on the labor market tightness factor, $\beta^{\theta}$. $\beta^{M}$ is market beta; BM is the book-tomarket ratio; $\mathrm{ME}$ is the market equity decile; $\mathrm{RU}$ is the 12-month return runup, in percent; $\mathrm{AG}$, IK, and $\mathrm{HN}$ are the asset growth, investment, and new hiring rates, respectively, all shown in percent. Mean characteristics are calculated in each annual cross-section and then averaged. The sample period is 1954-2012 except for variables that use Compustat data (BM, $\mathrm{AG}, \mathrm{IK}$, and HN) where it is $1960-2012$.

\begin{tabular}{lrrrrrrrr}
\hline Decile & $\beta^{\theta}$ & $\beta^{M}$ & $\mathrm{BM}$ & $\mathrm{ME}$ & $\mathrm{RU}$ & $\mathrm{AG}$ & $\mathrm{IK}$ & $\mathrm{HN}$ \\
\hline Low & -0.80 & 1.35 & 0.89 & 4.84 & 15.44 & 12.92 & 32.59 & 6.36 \\
2 & -0.38 & 1.16 & 0.92 & 5.73 & 13.68 & 13.02 & 29.39 & 7.16 \\
3 & -0.23 & 1.07 & 0.91 & 6.09 & 12.67 & 11.01 & 27.34 & 5.70 \\
4 & -0.12 & 1.01 & 0.92 & 6.27 & 12.92 & 11.36 & 27.05 & 6.72 \\
5 & -0.03 & 1.00 & 0.92 & 6.22 & 13.37 & 11.17 & 26.08 & 5.00 \\
6 & 0.06 & 1.01 & 0.94 & 5.99 & 13.08 & 11.51 & 26.44 & 5.12 \\
7 & 0.16 & 1.04 & 0.94 & 5.84 & 13.35 & 11.30 & 27.35 & 5.94 \\
8 & 0.27 & 1.08 & 0.95 & 5.52 & 13.55 & 11.41 & 28.17 & 5.50 \\
9 & 0.45 & 1.17 & 0.94 & 4.98 & 13.71 & 12.23 & 29.54 & 6.95 \\
High & 0.91 & 1.33 & 0.92 & 3.99 & 16.13 & 12.63 & 32.87 & 6.86 \\
\hline
\end{tabular}




\section{Table III \\ Performance of Labor Market Tightness Portfolios}

This table reports average raw returns and alphas, in percent per month, and loadings from the fourfactor model regressions for the ten portfolios of stocks sorted on the basis of their loadings on the labor market tightness factor, as well as for the portfolio that is long the low decile and short the high group. The bottom row gives $t$-statistics for the low-high portfolio. Firms are assigned into deciles at the end of every month $\tau$ and the value-weighted portfolios are held without rebalancing for 12 months beginning in month $\tau+2$. Conditional alphas are intercepts from regression $R_{j, t}-R_{f, t}=$ $\alpha_{j}+\beta_{j}\left[\begin{array}{ll}1 & Z_{t-1}\end{array}\right]^{\prime}\left(R_{M, t}-R_{f, t}\right)+e_{j, \tau}$, where $j$ indexes portfolios, $t$ indexes months, $\beta_{j}$ is a $1 \times(k+1)$ parameter vector, and $Z_{t-1}$ is a $1 \times k$ instrument vector. Ferson and Schadt (FS) conditional alpha is computed using as instruments demeaned dividend yield, term spread, T-bill rate, and default spread. Boguth, Carlson, Fisher, and Simutin (BCFS) conditional alpha is computed by additionally including as instruments lagged 6- and 36-month market returns and average lagged 6- and 36-month betas of the portfolios. The sample period is 1954-2012.

\begin{tabular}{|c|c|c|c|c|c|c|c|c|c|c|}
\hline \multirow[b]{2}{*}{ Decile } & \multirow{2}{*}{$\begin{array}{r}\text { Raw } \\
\text { Return }\end{array}$} & \multicolumn{3}{|c|}{ Unconditional Alphas } & \multicolumn{2}{|c|}{ Cond. Alphas } & \multicolumn{4}{|c|}{ 4-Factor Loadings } \\
\hline & & CAPM & 3-Factor & 4-Factor & FS & BCFS & MKT & HML & SMB & UMD \\
\hline Low & 1.12 & 0.04 & 0.06 & 0.04 & 0.08 & 0.08 & 1.16 & -0.11 & 0.38 & 0.02 \\
\hline 2 & 1.09 & 0.13 & 0.13 & 0.13 & 0.11 & 0.11 & 1.05 & 0.01 & -0.02 & 0.00 \\
\hline 3 & 1.05 & 0.13 & 0.11 & 0.13 & 0.11 & 0.10 & 0.99 & 0.06 & -0.08 & -0.02 \\
\hline 4 & 1.01 & 0.11 & 0.09 & 0.09 & 0.10 & 0.10 & 0.95 & 0.07 & -0.10 & -0.01 \\
\hline 5 & 0.98 & 0.09 & 0.05 & 0.03 & 0.06 & 0.05 & 0.96 & 0.13 & -0.11 & 0.01 \\
\hline 6 & 0.96 & 0.06 & 0.03 & 0.01 & 0.04 & 0.04 & 0.97 & 0.09 & -0.11 & 0.03 \\
\hline 7 & 0.96 & 0.05 & 0.03 & 0.04 & 0.03 & 0.03 & 0.98 & 0.04 & -0.07 & -0.01 \\
\hline 8 & 0.94 & -0.01 & -0.02 & 0.03 & -0.01 & 0.00 & 1.01 & 0.00 & 0.02 & -0.05 \\
\hline 9 & 0.83 & -0.20 & -0.19 & -0.13 & -0.16 & -0.14 & 1.11 & -0.08 & 0.18 & -0.07 \\
\hline High & 0.65 & -0.47 & -0.46 & -0.37 & -0.40 & -0.38 & 1.18 & -0.19 & 0.62 & -0.09 \\
\hline Low-High & 0.47 & 0.51 & 0.52 & 0.41 & 0.48 & 0.47 & -0.02 & 0.07 & -0.24 & 0.11 \\
\hline t-statistic & {$[3.41]$} & {$[3.78]$} & [3.83] & {$[2.99]$} & {$[3.56]$} & {$[3.46]$} & {$[-0.62]$} & [1.41] & {$[-5.18]$} & [3.30] \\
\hline
\end{tabular}




\section{Table IV \\ Summary Statistics of Risk Factors}

This table reports summary statistics for the difference in returns on stocks with low and high loadings $\beta^{\theta}$ on the labor market tightness factor as well as for market excess return, and value, size and momentum factors. All data are monthly. Means and standard deviations are in percent. The sample period is 1954-2012.

\begin{tabular}{|c|c|c|c|c|c|c|c|}
\hline & \multirow[b]{2}{*}{ Mean } & \multirow[b]{2}{*}{$\begin{array}{l}\text { Standard } \\
\text { deviation }\end{array}$} & \multirow[b]{2}{*}{$\begin{array}{r}\text { Sharpe } \\
\text { ratio }\end{array}$} & \multicolumn{4}{|c|}{ Correlations } \\
\hline & & & & $\begin{array}{l}\text { Low-high } \\
\beta^{\theta} \text { return }\end{array}$ & $\begin{array}{l}\text { Mkt excess } \\
\text { return }\end{array}$ & $\begin{array}{l}\text { Value } \\
\text { factor }\end{array}$ & $\begin{array}{r}\text { Size } \\
\text { factor }\end{array}$ \\
\hline Low-high $\beta^{\theta}$ return & 0.47 & 3.60 & 0.13 & & & & \\
\hline Market excess return & 0.55 & 4.40 & 0.13 & -0.11 & & & \\
\hline Value factor & 0.38 & 2.75 & 0.14 & 0.08 & -0.27 & & \\
\hline Size factor & 0.20 & 2.95 & 0.07 & -0.22 & 0.28 & -0.21 & \\
\hline Momentum factor & 0.73 & 4.06 & 0.12 & 0.15 & -0.13 & -0.17 & -0.03 \\
\hline
\end{tabular}




\section{Table V \\ Robustness of Labor Market Tightness Portfolios}

This table reports average raw returns and alphas, in percent per month, four-factor loadings, and corresponding $t$-statistics for the portfolio that is long the decile of stocks with low loadings on the labor market tightness factor and short the decile with high loadings. In Panel A, firms are assigned into deciles at the end of May of year $T$ and are held from July of year $T$ to June of year $T+1$. In Panel B, firms are assigned into deciles at the end of every month $\tau$ and are held during month $\tau+2$. In Panel $\mathrm{C}$, firms are assigned into deciles at the end of every month $\tau$ and are held without rebalancing for 12 month beginning in month $\tau+3$. In Panel $\mathrm{D}$, firms are assigned into quintiles rather than deciles. In Panel E, firms below 20th percentile of NYSE market capitalization are excluded from the sample. In Panel F, labor market tightness factor is defined as the residual from a time-series regression of $\vartheta$ defined in equation (2) on change in industrial production, change in consumer price index, dividend yield, T-bill rate, term spread, and default spread. In Panel G, labor market tightness factor is defined as the residual from fitting log of labor market tightness to an ARMA(1,1) model. In Panel H, regression (3) is amended to also include size, value, and momentum factors. Conditional alphas are intercepts from regression $R_{j, t}-R_{f, t}=\alpha_{j}+\beta_{j}\left[\begin{array}{ll}1 & Z_{t-1}\end{array}\right]^{\prime}\left(R_{M, t}-R_{f, t}\right)+e_{j, \tau}$, where $j$ indexes portfolios, $t$ indexes months, $\beta_{j}$ is a $1 \times(k+1)$ parameter vector, and $Z_{t-1}$ is a $1 \times k$ instrument vector. Ferson and Schadt (FS) conditional alpha is computed using as instruments demeaned dividend yield, term spread, T-bill rate, and default spread. Boguth, Carlson, Fisher, and Simutin (BCFS) conditional alpha is computed by additionally including as instruments lagged 6- and 36-month market returns and average lagged 6- and 36-month betas of the portfolios. In all panels, portfolios are initially value-weighted. The sample period is 1954-2012.

\begin{tabular}{|c|c|c|c|c|c|c|c|c|c|c|}
\hline \multirow[b]{2}{*}{ Decile } & \multirow{2}{*}{$\begin{array}{r}\text { Raw } \\
\text { Return }\end{array}$} & \multicolumn{3}{|c|}{ Unconditional Alphas } & \multicolumn{2}{|c|}{ Cond Alphas } & \multicolumn{4}{|c|}{ 4-Factor Loadings } \\
\hline & & CAPM & 3-Factor & 4-Factor & FS & BCFS & MKT & HML & SMB & UMD \\
\hline \multicolumn{11}{|c|}{ A. Non-overlapping portfolios } \\
\hline Low-High & 0.55 & 0.59 & 0.51 & 0.47 & 0.50 & 0.50 & 0.01 & 0.24 & -0.25 & 0.04 \\
\hline t-statistic & {$[3.42]$} & [3.68] & {$[3.19]$} & {$[2.89]$} & {$[3.16]$} & {$[3.11]$} & {$[0.29]$} & {$[3.92]$} & {$[-4.50]$} & [0.94] \\
\hline \multicolumn{11}{|c|}{ B. One-month holding } \\
\hline Low-High & 0.51 & 0.58 & 0.61 & 0.46 & 0.54 & 0.52 & -0.06 & 0.04 & -0.28 & 0.16 \\
\hline t-statistic & {$[2.99]$} & {$[3.44]$} & {$[3.63]$} & {$[2.67]$} & {$[3.35]$} & {$[3.23]$} & {$[-1.42]$} & {$[0.67]$} & {$[-4.84]$} & {$[3.85]$} \\
\hline \multicolumn{11}{|c|}{ C. Two-months waiting } \\
\hline Low-High & 0.47 & 0.52 & 0.52 & 0.42 & 0.48 & 0.47 & -0.02 & 0.07 & -0.24 & 0.11 \\
\hline t-statistic & {$[3.49]$} & {$[3.84]$} & {$[3.90]$} & {$[3.08]$} & {$[3.62]$} & {$[3.52]$} & {$[-0.58]$} & {$[1.35]$} & {$[-5.17]$} & {$[3.23]$} \\
\hline \multicolumn{11}{|c|}{ D. Quintile portfolios } \\
\hline Low-High & 0.32 & 0.39 & 0.39 & 0.30 & 0.35 & 0.32 & -0.06 & 0.07 & -0.19 & 0.09 \\
\hline t-statistic & {$[2.82]$} & {$[3.44]$} & {$[3.44]$} & {$[2.60]$} & {$[3.13]$} & {$[2.90]$} & {$[-2.29]$} & {$[1.61]$} & {$[-4.91]$} & [3.33] \\
\hline \multicolumn{11}{|c|}{ E. Excluding micro caps } \\
\hline Low-High & 0.45 & 0.49 & 0.51 & 0.35 & 0.49 & 0.46 & -0.05 & 0.01 & -0.01 & 0.17 \\
\hline t-statistic & {$[3.72]$} & {$[4.05]$} & {$[4.15]$} & {$[2.84]$} & {$[4.08]$} & {$[3.88]$} & {$[-1.79]$} & {$[0.31]$} & {$[-0.22]$} & [5.54] \\
\hline \multicolumn{11}{|c|}{ F. Alternative definition 1 of $\vartheta$} \\
\hline Low-High & 0.44 & 0.48 & 0.50 & 0.46 & 0.47 & 0.46 & -0.04 & 0.02 & -0.19 & 0.04 \\
\hline t-statistic & {$[3.22]$} & {$[3.55]$} & {$[3.65]$} & {$[3.32]$} & {$[3.53]$} & {$[3.46]$} & {$[-1.30]$} & {$[0.44]$} & {$[-4.08]$} & {$[1.06]$} \\
\hline \multicolumn{11}{|c|}{ G. Alternative definition 2 of $\vartheta$} \\
\hline Low-High & 0.45 & 0.51 & 0.49 & 0.41 & 0.45 & 0.44 & -0.03 & 0.11 & -0.24 & 0.09 \\
\hline t-statistic & {$[3.28]$} & {$[3.68]$} & {$[3.58]$} & {$[2.87]$} & {$[3.29]$} & {$[3.20]$} & {$[-0.80]$} & {$[2.13]$} & {$[-4.92]$} & {$[2.70]$} \\
\hline \multicolumn{11}{|c|}{ H. Alternative computation of $\beta^{\theta}$} \\
\hline Low-High & 0.29 & 0.36 & 0.38 & 0.30 & 0.32 & 0.31 & -0.08 & 0.03 & -0.08 & 0.20 \\
\hline t-statistic & {$[2.36]$} & {$[2.90]$} & {$[3.04]$} & {$[2.55]$} & {$[2.62]$} & {$[2.54]$} & {$[-2.55]$} & {$[0.70]$} & {$[-1.82]$} & {$[6.46]$} \\
\hline
\end{tabular}


Table VI

Fama-MacBeth Regressions of Annual Stock Returns

This table reports the results of annual Fama-MacBeth regressions. Stock returns from July of year $T$ to June of year $T+1$ are regressed on $\beta^{\theta}$, loading on the labor market tightness factor measured as of the end of May of year $T ; \beta^{M}$, market beta measured as of the same time; ME, $\log$ of market equity measured as of the end of June of year $T$; BM, log of the ratio of book equity to market equity measured following Davis, Fama, and French (2000); RU, 12-month stock return ending in June of year $T$; and $\mathrm{HN}, \mathrm{IK}$, and $\mathrm{AG}$, the new hiring, investment, and asset growth rates, respectively, defined as in Belo, Lin, and Bazdresch (2013). Reported are average coefficients and the corresponding Newey and West (1987) $t$-statistics. Details of variable definitions are in Appendix A. The sample period is 1954-2012.

\begin{tabular}{|c|c|c|c|c|c|c|c|c|}
\hline Reg & $\beta^{\theta}$ & $\beta^{M}$ & ME & $\mathrm{BM}$ & $\mathrm{RU}$ & $\mathrm{HN}$ & IK & $\mathrm{AG}$ \\
\hline \multirow[t]{2}{*}{ (1) } & -0.028 & 0.000 & -0.015 & & & & & \\
\hline & {$[-2.46]$} & {$[-0.01]$} & {$[-2.70]$} & & & & & \\
\hline \multirow[t]{2}{*}{ (2) } & -0.030 & 0.009 & -0.011 & 0.035 & & & & \\
\hline & {$[-2.30]$} & {$[0.67]$} & {$[-1.95]$} & {$[4.20]$} & & & & \\
\hline \multirow[t]{2}{*}{$(3)$} & -0.040 & 0.010 & -0.012 & 0.037 & 0.066 & & & \\
\hline & {$[-2.85]$} & {$[0.72]$} & {$[-2.22]$} & {$[4.65]$} & {$[3.46]$} & & & \\
\hline \multirow[t]{2}{*}{ (4) } & -0.043 & 0.010 & -0.012 & 0.032 & 0.067 & -0.050 & & \\
\hline & {$[-3.01]$} & {$[0.72]$} & {$[-2.29]$} & {$[4.09]$} & [3.38] & {$[-3.48]$} & & \\
\hline \multirow[t]{2}{*}{ (5) } & -0.048 & 0.011 & -0.013 & 0.033 & 0.066 & & -0.017 & \\
\hline & {$[-2.94]$} & {$[0.78]$} & {$[-2.30]$} & {$[4.37]$} & {$[3.32]$} & & {$[-1.54]$} & \\
\hline \multirow[t]{2}{*}{ (6) } & -0.040 & 0.012 & -0.011 & 0.032 & 0.066 & & & -0.075 \\
\hline & {$[-2.75]$} & {$[0.83]$} & {$[-2.13]$} & {$[4.10]$} & {$[3.36]$} & & & {$[-5.02]$} \\
\hline \multirow[t]{2}{*}{ (7) } & -0.046 & 0.011 & -0.012 & 0.028 & 0.068 & 0.004 & 0.014 & -0.091 \\
\hline & {$[-3.01]$} & {$[0.77]$} & {$[-2.25]$} & {$[3.67]$} & {$[3.36]$} & {$[0.26]$} & {$[1.16]$} & {$[-4.66]$} \\
\hline
\end{tabular}


Table VII

Performance of Labor Market Tightness Portfolios: Industry-Level Analysis

This table reports in Panel A average raw returns and alphas, in percent per month, and loadings from the four-factor model regressions for the ten portfolios of stocks sorted within each of the 48 Ken French-defined industries on the basis of their loadings on the labor market tightness factor. Each of the ten portfolios thus has similar industry composition. Panel B repeats the analysis for the ten portfolios obtained by sorting 48 value-weighted industry portfolios from Ken French's data library on the basis of their loadings on the labor market tightness factor. The table also shows returns, alphas, and loadings for the portfolio that is long the low decile and short the high group. The bottom row of each panel gives $t$-statistics for the low-high portfolio. Firms (in Panel A) or industries (in Panel B) are assigned into deciles at the end of every month $\tau$ and are held without rebalancing for twelve months beginning in month $\tau+2$. Conditional alphas are intercepts from regression $R_{j, t}-R_{f, t}=\alpha_{j}+\beta_{j}\left[1 Z_{t-1}\right]^{\prime}\left(R_{M, t}-R_{f, t}\right)+e_{j, \tau}$, where $j$ indexes portfolios, $t$ indexes months, $\beta_{j}$ is a $1 \times(k+1)$ parameter vector, and $Z_{t-1}$ is a $1 \times k$ instrument vector. Ferson and Schadt (FS) conditional alpha is computed using as instruments demeaned dividend yield, term spread, T-bill rate, and default spread. Boguth, Carlson, Fisher, and Simutin (BCFS) conditional alpha is computed by additionally including as instruments lagged 6- and 36-month market returns and average lagged 6- and 36-month betas of the portfolios. The sample period is 1954-2012.

\begin{tabular}{|c|c|c|c|c|c|c|c|c|c|c|}
\hline \multirow[b]{2}{*}{ Decile } & \multirow{2}{*}{$\begin{array}{r}\text { Raw } \\
\text { Return }\end{array}$} & \multicolumn{3}{|c|}{ Unconditional Alphas } & \multicolumn{2}{|c|}{ Cond. Alphas } & \multicolumn{4}{|c|}{ 4-Factor Loadings } \\
\hline & & $\mathrm{CAPM}$ & 3-Factor & 4-Factor & FS & BCFS & MKT & HML & SMB & UMD \\
\hline \multicolumn{11}{|c|}{ A. Portfolios of Stocks Sorted by Labor Market Tightness Loadings Within Industries } \\
\hline Low & 1.10 & 0.09 & 0.04 & 0.02 & 0.10 & 0.09 & 1.10 & 0.06 & 0.20 & 0.03 \\
\hline 2 & 1.06 & 0.10 & 0.06 & 0.07 & 0.09 & 0.09 & 1.03 & 0.06 & 0.06 & -0.01 \\
\hline 3 & 1.01 & 0.08 & 0.07 & 0.11 & 0.07 & 0.07 & 0.99 & 0.01 & -0.05 & -0.04 \\
\hline 4 & 0.99 & 0.08 & 0.07 & 0.08 & 0.06 & 0.07 & 0.97 & 0.03 & -0.07 & -0.01 \\
\hline 5 & 0.97 & 0.06 & 0.06 & 0.07 & 0.04 & 0.04 & 0.98 & 0.03 & -0.12 & -0.02 \\
\hline 6 & 0.99 & 0.08 & 0.08 & 0.08 & 0.06 & 0.05 & 0.98 & 0.02 & -0.12 & 0.00 \\
\hline 7 & 0.93 & 0.01 & 0.00 & 0.00 & -0.01 & -0.01 & 0.99 & 0.03 & -0.08 & 0.00 \\
\hline 8 & 0.92 & -0.01 & -0.03 & -0.03 & -0.01 & -0.01 & 1.00 & 0.05 & -0.05 & 0.00 \\
\hline 9 & 0.91 & -0.06 & -0.09 & -0.06 & -0.04 & -0.03 & 1.05 & 0.05 & 0.04 & -0.04 \\
\hline High & 0.73 & -0.27 & -0.34 & -0.31 & -0.25 & -0.25 & 1.08 & 0.09 & 0.27 & -0.03 \\
\hline Low-High & 0.37 & 0.36 & 0.39 & 0.33 & 0.35 & 0.34 & 0.02 & -0.03 & -0.07 & 0.06 \\
\hline t-statistic & [3.84] & {$[3.76]$} & {$[4.01]$} & {$[3.36]$} & {$[3.79]$} & [3.63] & {$[0.96]$} & {$[-0.78]$} & {$[-1.98]$} & [2.40] \\
\hline \multicolumn{11}{|c|}{ B. Portfolios of Industries Sorted by Labor Market Tightness Loadings } \\
\hline Low & 1.30 & 0.34 & 0.23 & 0.13 & 0.29 & 0.27 & 1.03 & 0.22 & 0.25 & 0.11 \\
\hline 2 & 1.14 & 0.19 & 0.10 & 0.10 & 0.15 & 0.14 & 1.00 & 0.16 & 0.16 & 0.01 \\
\hline 3 & 1.13 & 0.18 & 0.08 & 0.07 & 0.15 & 0.14 & 1.00 & 0.16 & 0.21 & 0.02 \\
\hline 4 & 1.11 & 0.17 & 0.08 & 0.05 & 0.14 & 0.13 & 0.99 & 0.17 & 0.23 & 0.03 \\
\hline 5 & 1.08 & 0.13 & 0.04 & 0.05 & 0.11 & 0.10 & 1.00 & 0.14 & 0.20 & -0.01 \\
\hline 6 & 1.05 & 0.09 & 0.00 & 0.04 & 0.06 & 0.06 & 1.03 & 0.14 & 0.17 & -0.04 \\
\hline 7 & 1.04 & 0.07 & -0.03 & 0.01 & 0.03 & 0.03 & 1.03 & 0.16 & 0.18 & -0.04 \\
\hline 8 & 1.09 & 0.12 & 0.00 & 0.05 & 0.06 & 0.06 & 1.05 & 0.19 & 0.17 & -0.06 \\
\hline 9 & 0.90 & -0.08 & -0.21 & -0.11 & -0.15 & -0.14 & 1.05 & 0.19 & 0.21 & -0.11 \\
\hline High & 0.96 & -0.03 & -0.16 & -0.13 & -0.09 & -0.10 & 1.05 & 0.19 & 0.32 & -0.03 \\
\hline Low-High & 0.34 & 0.37 & 0.39 & 0.26 & 0.38 & 0.37 & -0.02 & 0.03 & -0.07 & 0.13 \\
\hline t-statistic & {$[2.37]$} & {$[2.55]$} & {$[2.60]$} & {$[1.71]$} & {$[2.54]$} & {$[2.45]$} & {$[-0.48]$} & {$[0.56]$} & {$[-1.41]$} & {$[3.67]$} \\
\hline
\end{tabular}


Table VIII

\section{Benchmark Parameter Calibration}

This table lists the parameter values of the benchmark calibration. The model is based on a monthly frequency.

\begin{tabular}{lcc}
\hline Parameter & Symbol & Value \\
\hline Labor Market &
\end{tabular}

Workers quit rate

Matching function elasticity

$s \quad 0.022$

Bargaining power of worker

$\xi \quad 1.27$

Benefit of being unemployed

$\eta \quad 0.1$

$b \quad 0.71$

Returns to scale of labor

Flow cost of vacancy posting

Flow cost of firing

Fixed operating costs

$\alpha \quad 0.75$

$\kappa_{h} \quad 0.4$

$\kappa_{f} \quad 0.2$

f $\quad 0.13$

\section{Shocks}

Persistence of aggregate productivity shock

Volatility of aggregate productivity shock

Persistence of matching efficiency shock

Volatility of matching efficiency shock

Persistence of idiosyncratic productivity shock

Volatility of idiosyncratic productivity shock

$\begin{array}{ll}\rho_{x} & 0.9830 \\ \sigma_{x} & 0.005 \\ \rho_{p} & 0.9473 \\ \sigma_{p} & 0.0426 \\ \rho_{z} & 0.96 \\ \sigma_{z} & 0.072\end{array}$

\section{Pricing Kernel}

Time discount rate

Price of risk of aggregate productivity shock

Price of risk of matching efficiency shock

Sensitivity of matching efficiency shock

Interest rate sensitivity

$\begin{array}{ll}\beta & 0.9935 \\ \gamma_{x} & 1 \\ \gamma_{p, 0} & -5 \\ \gamma_{p, 1} & 5 \\ \phi & -0.0225\end{array}$


Table IX

\section{Aggregate and Firm-Specific Target Moments}

This table summarizes the empirical aggregate and firm-specific moments used to calibrate model parameters.

\begin{tabular}{lcc}
\hline Moment & Data & Model \\
\hline Aggregate Labor Market & & \\
Unemployment rate & 0.058 & 0.058 \\
Hiring rate & 0.035 & 0.035 \\
Layoff rate & 0.014 & 0.013 \\
Labor market tightness & 0.634 & 0.635 \\
Volatility of labor market tightness factor & 0.055 & 0.053 \\
Labor share of income & 0.717 & 0.706 \\
Volatility of aggregate wages to aggregate output & 0.520 & 0.517 \\
Aggregate profits to aggregate output & 0.110 & 0.110 \\
Firm-Level Employment & & \\
Volatility of annual employment growth rates & 0.236 & 0.219 \\
Skewness of annual employment growth rates & 0.123 & 0.140 \\
Fraction of firms with zero annual employment growth rates & 0.097 & 0.077 \\
Asset Prices & & \\
Average risk-free rate & 0.010 & 0.010 \\
Volatility of risk-free rate & 0.021 & 0.021 \\
Average market return & 0.081 & 0.088 \\
Stock market volatility & 0.176 & 0.174 \\
\hline
\end{tabular}


Table X

\section{Portfolio Returns of the Benchmark Model}

This table compares our benchmark model performance with data. All numbers are expressed in percentage terms. Return refers to future portfolio equity return. Under benchmark calibration, we simulate panels of firms and compute their theoretical loadings on the labor market tightness factor. We sort portfolios according to their LMT loadings and calculate the realized and expected future annualized equity returns. The benchmark model produces monotonically decreasing portfolio returns, which resembles the data.

\begin{tabular}{lrrrrrrr}
\hline & \multicolumn{3}{c}{ Data } & & \multicolumn{3}{c}{ Model } \\
\cline { 2 - 3 } Decile & $\beta_{\theta}$ & Return & $\alpha_{C A P M}$ & & $\beta_{\theta}$ & Return & $\alpha_{C A P M}$ \\
\hline Low & -0.74 & 1.10 & 0.09 & & -0.84 & 1.09 & 0.23 \\
2 & -0.39 & 1.06 & 0.10 & & -0.64 & 1.02 & 0.19 \\
3 & -0.23 & 1.01 & 0.08 & & -0.48 & 0.99 & 0.16 \\
4 & -0.12 & 0.99 & 0.08 & & -0.39 & 0.96 & 0.15 \\
5 & -0.03 & 0.97 & 0.06 & -0.23 & 0.91 & 0.13 \\
6 & 0.06 & 0.99 & 0.08 & -0.18 & 0.92 & 0.12 \\
7 & 0.16 & 0.93 & 0.01 & & 0.00 & 0.86 & 0.00 \\
8 & 0.28 & 0.92 & -0.01 & & 0.08 & 0.85 & -0.01 \\
9 & 0.45 & 0.91 & -0.06 & & 0.29 & 0.79 & -0.04 \\
High & 0.85 & 0.73 & -0.27 & & 0.61 & 0.73 & -0.08 \\
Low-High & -1.59 & 0.37 & 0.36 & -1.45 & 0.36 & 0.31 \\
\hline
\end{tabular}


Table XI

\section{Portfolio Returns across Alternative Calibrations}

This table compares the model-simulated expected future equity returns of portfolio deciles sorted on labor market tightness loadings across alternative calibrations. Model (1) - (2) adjust the structure of the exogenous pricing kernel; Model (3) - (4) change the aggregate shock processes; Model (5) - (9) vary the parameters closely tied to the labor market. In Model (1), we assume that the matching efficiency shocks are not priced by setting $\gamma_{p, 0}=0$. We also raise the price of risk of the productivity shocks to 10 , i.e. $\gamma_{x}=10$, so that the model-implied Sharpe ratio of the pricing kernel remains. In Model (2), we set $\gamma_{p, 1}=0$ so that the aggregate matching efficiency shocks have constant price of risk. In Model (3) and (4), the matching efficiency shocks $p$ and the aggregate productivity shocks $x$ are turned off respectively. In Model (5), we break the dependency of the wage rate on the labor market equilibrium by fixing the $\theta_{t}$ term in the wage rate constant to the average level of labor market tightness. In Model (6), we raise the bargaining power of workers to $\eta=0.5$ and adjust the mess of the labor force accordingly to match the unemployment rate of 5.8\%. In Model (7), we set the firing cost $\kappa_{f}=0$ so that it is costless to downsize. In Model (8), we lower the unit vacancy posting cost $\kappa_{h}$ from 0.4 to 0.3 and adjust the size of the labor force to match the unemployment rate. In Model (9), we remove the fixed operating costs by setting $f_{0}=0$.

\begin{tabular}{lrrrrrrrrr}
\hline Decile & $(1)$ & $(2)$ & $(3)$ & $(4)$ & $(5)$ & $(6)$ & $(7)$ & $(8)$ & $(9)$ \\
\hline Low & 0.89 & 1.00 & 0.86 & 1.08 & 1.13 & 0.99 & 1.05 & 1.06 & 0.94 \\
2 & 0.91 & 0.97 & 0.87 & 1.03 & 1.10 & 0.96 & 1.00 & 1.01 & 0.92 \\
3 & 0.91 & 0.95 & 0.85 & 1.00 & 1.08 & 0.94 & 0.96 & 0.97 & 0.91 \\
4 & 0.93 & 0.94 & 0.87 & 0.98 & 1.05 & 0.94 & 0.95 & 0.95 & 0.90 \\
5 & 0.93 & 0.91 & 0.87 & 0.94 & 1.03 & 0.91 & 0.90 & 0.91 & 0.88 \\
6 & 0.94 & 0.91 & 0.87 & 0.94 & 0.99 & 0.91 & 0.90 & 0.91 & 0.88 \\
7 & 0.97 & 0.88 & 0.88 & 0.89 & 0.96 & 0.88 & 0.86 & 0.86 & 0.86 \\
8 & 0.97 & 0.87 & 0.87 & 0.88 & 0.93 & 0.88 & 0.84 & 0.85 & 0.85 \\
9 & 0.96 & 0.84 & 0.86 & 0.83 & 0.85 & 0.85 & 0.80 & 0.80 & 0.83 \\
High & 0.98 & 0.78 & 0.88 & 0.77 & 0.69 & 0.80 & 0.74 & 0.74 & 0.79 \\
Low-High & -0.09 & 0.22 & -0.02 & 0.31 & 0.44 & 0.18 & 0.31 & 0.32 & 0.15 \\
\hline
\end{tabular}


Table XII

\section{Portfolio Characteristics on Cash Flow Cyclicality}

This table reports the cash flow cyclicality characteristics of portfolios sorted on loadings on labor market tightness both in the data and in the model simulation. The first 3 columns reports estimations from data: time series correlations of variables shown in column headings calculated for year $t$ on contemporaneous log changes in labor market tightness. Firms are assigned into decile portfolios within industries on the basis of their loadings on the labor market tightness factor computed over $t-3$ to $t-1$. Variable definitions are provided in Appendix A. The last 3 columns are from model simulations. In the model, CF is computed as dividend (profit); ROA is the before-wage profit over firm size N; DY is computed as in the data. In the first table below, we compute the correlations of $\mathrm{CF}$, ROA, DY with respect to labor market tightness. In the second table, we compute the regression coefficient of $\mathrm{CF}$, ROA, DY on labor market tightness.

\begin{tabular}{lrrrrrr}
\hline Decile & CF1 & ROA & DY & CFsim & ROAsim & DYsim \\
\hline Low & -0.13 & -0.23 & -0.02 & -0.06 & 0.03 & -0.02 \\
2 & -0.03 & 0.11 & -0.01 & 0.05 & 0.44 & -0.02 \\
3 & -0.01 & 0.15 & 0.01 & 0.08 & 0.22 & -0.03 \\
4 & -0.09 & 0.09 & 0.03 & -0.01 & 0.00 & -0.02 \\
5 & 0.01 & 0.16 & 0.02 & 0.00 & 0.02 & -0.02 \\
6 & -0.00 & 0.19 & 0.02 & 0.28 & 0.58 & -0.03 \\
7 & 0.10 & 0.30 & 0.02 & 0.09 & 0.47 & 0.01 \\
8 & 0.05 & 0.20 & 0.03 & 0.27 & 0.57 & -0.00 \\
9 & 0.05 & 0.06 & 0.03 & 0.23 & 0.73 & 0.01 \\
High & 0.19 & 0.39 & 0.04 & 0.26 & 0.91 & 0.01 \\
Low-High & -0.32 & -0.62 & -0.05 & -0.33 & -0.88 & -0.03 \\
\hline
\end{tabular}


Table XIII

Forecasting Economic Activity with Labor Market Tightness

This table reports results of regressions of consumption growth (Panel A), aggregate output growth (Panel B) and aggregate wage growth (Panel C) over years $\tau$ to $\tau+t, t \in(0,1,2,3)$ on change in labor market tightness and total factor productivity over year $\tau$. Shown are coefficients on the change in labor market tightness $(\vartheta)$, corresponding t-statistics, and adjusted $\mathrm{R}$-squared from the regressions. Consumption is taken from NIPA Table 1.1.3, aggregate output is the gross domestic product from FRED, aggregate wage is the wages and salary accruals form FRED, and total factor productivity is from is the business sector TFP from the John Fernald website at the Federal Reserve Bank of San Francisco. The sample period is $1954-2012$.

\begin{tabular}{lccrr}
\multicolumn{5}{c}{ Forecast horizon, years } \\
\cline { 2 - 5 } & \multicolumn{5}{c}{1} & 2 & 3 \\
\hline A. Predicting consumption growth \\
$\vartheta$ & 0.022 & -0.027 & -0.038 & -0.032 \\
t-statistic & {$[3.75]$} & {$[-2.88]$} & $-3.51]$ & {$[-2.71]$} \\
$\mathrm{R}^{2}$ & 66.35 & 15.16 & 11.06 & 3.35 \\
B. Predicting & aggregate output & growth \\
$\vartheta$ & 0.039 & 0.033 & 0.019 & 0.009 \\
t-statistic & {$[6.48]$} & {$[4.94]$} & {$[2.27]$} & {$[1.00]$} \\
$\mathrm{R}^{2}$ & 40.98 & 28.43 & 3.41 & 0.00 \\
C. Predicting & aggregate wage bill growth & \\
$\vartheta$ & 0.025 & 0.049 & 0.051 & 0.044 \\
t-statistic & {$[2.75]$} & {$[5.79]$} & {$[4.20]$} & {$[3.14]$} \\
$\mathrm{R}^{2}$ & 29.45 & 37.95 & 18.43 & 10.36 \\
\hline \multicolumn{5}{c}{}
\end{tabular}




\section{Internet Appendix to A Labor Capital Asset Pricing Model}

In this appendix, we summarize robustness tests of the negative relation between stock return loadings on changes in labor market tightness and future equity returns. We also provide additional empirical results.

\section{A. Controlling for Liquidity and Profitability Factors}

? show that stocks with higher liquidity risk earn higher returns, and ? documents that more profitable firms generate superior future stock returns. To ensure that our results are not driven by liquidity or profitability risk, we repeat the portfolio sort analysis of Table III while controlling for these two sources of risk. As before, we assign stocks into deciles conditional on their loadings on the labor market tightness factor and obtain monthly time series of future returns for each of the resulting ten portfolios. We use the same models as before to calculate unconditional and conditional alphas, but include liquidity or profitability factor as an additional regressor in each of the models. ${ }^{19}$ The data on the two factors are available starting only in 1960s, which shortens our sample by as much as 14 years.

Table AI shows that our results are robust to controlling for the liquidity and profitability factors. The negative relation between labor market tightness loadings and future stock returns is economically important and statistically significant in all regressions. The difference in future raw and risk-adjusted returns of portfolios with low and high loadings range from $0.33 \%$ and $0.47 \%$ monthly.

\section{B. Post-Ranking Loadings on Labor Market Tightness}

Table AII summarizes post-ranking $\beta^{\theta}$ loadings of the labor market tightness portfolios. For each portfolio, we obtain monthly time series of returns from January 1954 until December 2012. We then regress excess returns of each group annually on the market and the labor market tightness factors, including two ? lags to account for any effects due to non-synchronous trading. We average betas across the years to obtain average $\beta^{\theta}$ loadings for each portfolio. We show results for deciles in Panel $\mathrm{A}$ and quintiles in Panel B. The differences in post-ranking betas of the bottom and top groups is sizeable although muted relative to the spread in the ranking betas shown in Table II. Importantly, in both Panels a positive relation emerges between ranking and post-ranking betas.

\section{Controlling for Market Beta}

In Table AIII we evaluate the relation between loadings $\beta^{\theta}$ on the labor market tightness factor and future equity returns conditional on stocks' market betas $\beta^{M}$. We sort firms into quintiles based on their $\beta^{\theta}$ and $\beta^{M}$ loadings computed as of the end of month $\tau$ and hold the resulting 25 valueweighted portfolios without rebalancing for 12 months beginning in month $\tau+2$. Table AIII shows that irrespective of whether we consider independent sorts or dependent sorts (e.g., first on $\beta^{M}$ and then by $\beta^{\theta}$ within each market beta quintile), stocks with low loadings on the labor market tightness factor significantly outperform stocks with high loadings.

\section{Controlling for Components of Labor Market Tightness and for Industrial Production}

The labor market tightness is composed for three components: vacancy index, unemployment rate, and labor force participation rate. The negative relation between labor market tightness loadings and future stock returns that we document can plausibly be driven by just one of these components rather

\footnotetext{
${ }^{19}$ Liquidity and profitability factors are from http://faculty.chicagobooth.edu/lubos.pastor/research/ and http://rnm.simon.rochester.edu/data_lib/index.html, respectively.
} 
than the combination of them that is the labor market tightness. It could could also be driven by changes in industrial production, with which the labor market tightness factor is highly correlated (see table (I). To explore whether this is the case, we first estimate loadings from a two-factor regression of stock excess returns on market excess returns and log changes in either vacancy index $\left(\beta^{V a c}\right)$, unemployment rate $\left(\beta^{U n e m p}\right)$, labor force participation rate $\left(\beta^{L F P R}\right)$, or industrial production $\left(\beta^{I P}\right)$. Following the same methodology used in the rest of the paper, we next study future performance of portfolios formed on the basis of these loadings and also run Fama-MacBeth regressions of annual stock returns on the lagged loadings and control variables. Tables AIV and AV show that none of the considered loadings relate robustly to future equity returns. Loadings on the vacancy factor relate negatively but weakly to future stock returns, and loadings on the unemployment rate factor relate positively but also weakly. There is no convincing evidence that loadings on either the labor force participation factor or the industrial production factor relate to future returns. Overall, the results suggest that the inverse relation between labor market tightness loadings and future stock returns is not driven by vacancies, unemployment rates, or labor force participation rates alone but rather by their interaction: the labor market tightness.

\section{E. Loadings on 48 Industry Portfolios}

In Table AVI, we summarize labor market tightness statistics for 48 value-weighted industry portfolios from Ken French's data library. We calculate unconditional loadings on the labor market tightness factor as well as average conditional betas from rolling three-year regressions and the corresponding standard deviations. We also report the fraction of months an industry falls into the high and the low $\beta^{\theta}$ quintiles. Differences in loadings on labor market tightness across industries are small, with average conditional betas falling in a tight range from - 0.097 (Precious Metals) to 0.071 (Real Estate). Even industries with lowest and highest average loadings exhibit significant time variation in $\beta^{\theta}$, suggesting that industry return sensitivities to changes in labor market tightness vary strongly over time, conceivably in response to changes in the underlying economics of the industry. For example, the Precious Metals industry has both the lowest unconditional and average conditional loadings but it still falls in the top $\beta^{\theta}$ quintile $21 \%$ of the time. Overall, the results suggest considerable heterogeneity and time variation in loadings on the labor market tightness across industries. 
Table AI

\section{Performance of Labor Market Tightness Portfolios: Controlling for Liquidity and Profitability Factors}

This table reports average raw returns and alphas, in percent per month, and loadings from the fivefactor model regressions for the ten portfolios of stocks sorted on the basis of their loadings on the labor market tightness factor, as well as for the portfolio that is long the low decile and short the high group. In Panel A, all alphas are computed by including the Pastor-Stambaugh liquidity factor (LIQ) in regressions. In Panel B, all alphas are computed by including the Novy-Marx profitability factor (PMU). The bottom row of each Panel gives $t$-statistics for the low-high portfolio. Firms are assigned into deciles at the end of every month $\tau$ and the value-weighted portfolios are held without rebalancing for 12 months beginning in month $\tau+2$. Conditional alphas are intercepts from regression $R_{j, t}-R_{f, t}=\alpha_{j}+\beta_{j}\left[\begin{array}{ll}1 & Z_{t-1}\end{array}\right]^{\prime}\left(R_{M, t}-R_{f, t}\right)+\gamma_{j} F_{t}+e_{j, \tau}$, where $j$ indexes portfolios, $t$ indexes months, $\beta_{j}$ is a $1 \times(k+1)$ parameter vector, $Z_{t-1}$ is a $1 \times k$ instrument vector, and $F_{t}$ is either the liquidity factor (in Panel A) or the profitability factor (in Panel B). Ferson and Schadt (FS) conditional alpha is computed using as instruments demeaned dividend yield, term spread, T-bill rate, and default spread. Boguth, Carlson, Fisher, and Simutin (BCFS) conditional alpha is computed by additionally including as instruments lagged 6- and 36-month market returns and average lagged 6- and 36-month betas of the portfolios. The sample period is 01:1968-12:2012 in Panel A, and 07:1963-12:2012 in Panel B.

\begin{tabular}{|c|c|c|c|c|c|c|c|c|c|c|c|}
\hline \multicolumn{12}{|c|}{ A. Controlling for Pastor-Stambaugh liquidity factor } \\
\hline \multirow[b]{2}{*}{ Decile } & \multirow{2}{*}{$\begin{array}{c}\text { Raw } \\
\text { Return }\end{array}$} & \multicolumn{3}{|c|}{ Uncond. Alphas: Liquidity + } & \multicolumn{2}{|c|}{ Cond. Alphas } & \multicolumn{4}{|c|}{ 5-Factor Loadings } & \multirow[b]{2}{*}{ LIQ } \\
\hline & & Market & 3-Factor & 4-Factor & $\mathrm{FS}$ & BCFS & MKT & HML & SMB & UMD & \\
\hline Low & 1.00 & 0.01 & 0.05 & 0.03 & 0.05 & 0.05 & 1.17 & -0.14 & 0.38 & 0.02 & 0.02 \\
\hline 2 & 1.03 & 0.13 & 0.12 & 0.13 & 0.11 & 0.11 & 1.05 & 0.01 & -0.02 & -0.01 & 0.04 \\
\hline 3 & 0.97 & 0.10 & 0.08 & 0.10 & 0.08 & 0.08 & 0.99 & 0.06 & -0.09 & -0.02 & 0.03 \\
\hline 4 & 0.96 & 0.11 & 0.09 & 0.09 & 0.09 & 0.09 & 0.97 & 0.08 & -0.12 & -0.01 & 0.03 \\
\hline 5 & 0.92 & 0.10 & 0.04 & 0.03 & 0.07 & 0.06 & 0.96 & 0.15 & -0.11 & 0.01 & 0.01 \\
\hline 6 & 0.93 & 0.11 & 0.08 & 0.05 & 0.09 & 0.08 & 0.97 & 0.10 & -0.11 & 0.03 & -0.02 \\
\hline 7 & 0.89 & 0.08 & 0.07 & 0.08 & 0.06 & 0.06 & 0.97 & 0.04 & -0.07 & -0.01 & -0.06 \\
\hline 8 & 0.87 & 0.03 & 0.02 & 0.07 & 0.02 & 0.03 & 1.01 & 0.00 & 0.03 & -0.06 & -0.08 \\
\hline 9 & 0.73 & -0.16 & -0.15 & -0.09 & -0.14 & -0.12 & 1.12 & -0.08 & 0.19 & -0.07 & -0.10 \\
\hline High & 0.53 & -0.43 & -0.40 & -0.32 & -0.35 & -0.34 & 1.16 & -0.22 & 0.64 & -0.09 & -0.12 \\
\hline Low-High & 0.47 & 0.44 & 0.45 & 0.34 & 0.40 & 0.39 & 0.01 & 0.08 & -0.25 & 0.11 & 0.14 \\
\hline t-statistic & {$[2.82]$} & {$[2.62]$} & {$[2.67]$} & {$[2.03]$} & {$[2.41]$} & {$[2.35]$} & {$[0.24]$} & {$[1.29]$} & {$[-4.70]$} & {$[2.99]$} & {$[3.15]$} \\
\hline
\end{tabular}

\section{B. Controlling for Novy-Marx profitability factor}

\begin{tabular}{|c|c|c|c|c|c|c|c|c|c|c|c|}
\hline \multirow[b]{2}{*}{ Decile } & \multirow{2}{*}{$\begin{array}{r}\text { Raw } \\
\text { Return }\end{array}$} & \multicolumn{3}{|c|}{ Uncond. Alphas: Profitability + } & \multicolumn{2}{|c|}{ Cond. Alphas } & \multicolumn{4}{|c|}{ 5-Factor Loadings } & \multirow[b]{2}{*}{$\mathrm{PMU}$} \\
\hline & & Market & 3-Factor & 4-Factor & FS & BCFS & MKT & HML & SMB & UMD & \\
\hline Low & 1.05 & 0.04 & 0.09 & 0.07 & 0.06 & 0.06 & 1.17 & -0.15 & 0.39 & 0.02 & -0.10 \\
\hline 2 & 1.03 & 0.12 & 0.09 & 0.09 & 0.10 & 0.09 & 1.05 & 0.04 & -0.01 & 0.00 & 0.08 \\
\hline 3 & 0.99 & 0.12 & 0.07 & 0.08 & 0.10 & 0.09 & 1.00 & 0.09 & -0.08 & -0.02 & 0.09 \\
\hline 4 & 0.97 & 0.11 & 0.06 & 0.07 & 0.10 & 0.09 & 0.97 & 0.10 & -0.11 & 0.00 & 0.08 \\
\hline 5 & 0.93 & 0.09 & 0.00 & -0.01 & 0.07 & 0.06 & 0.96 & 0.17 & -0.11 & 0.01 & 0.09 \\
\hline 6 & 0.93 & 0.07 & 0.01 & -0.02 & 0.06 & 0.05 & 0.98 & 0.13 & -0.11 & 0.03 & 0.11 \\
\hline 7 & 0.89 & 0.00 & -0.03 & -0.03 & -0.01 & -0.01 & 0.98 & 0.07 & -0.07 & -0.01 & 0.12 \\
\hline 8 & 0.89 & -0.03 & -0.06 & -0.02 & -0.04 & -0.02 & 1.02 & 0.03 & 0.02 & -0.05 & 0.12 \\
\hline 9 & 0.77 & -0.20 & -0.17 & -0.10 & -0.18 & -0.15 & 1.12 & -0.10 & 0.17 & -0.07 & -0.04 \\
\hline High & 0.59 & -0.42 & -0.35 & -0.26 & -0.37 & -0.36 & 1.16 & -0.29 & 0.64 & -0.09 & -0.22 \\
\hline Low-High & 0.45 & 0.47 & 0.44 & 0.33 & 0.43 & 0.42 & 0.02 & 0.13 & -0.25 & 0.12 & 0.13 \\
\hline t-statistic & [2.91] & {$[2.96]$} & {$[2.78]$} & {$[2.05]$} & {$[2.77]$} & {$[2.67]$} & {$[0.46]$} & {$[2.25]$} & {$[-4.86]$} & {$[3.26]$} & [1.80] \\
\hline
\end{tabular}




\section{Table AII}

\section{Post-Ranking Betas of Labor Market Tightness Portfolios}

This table reports post-ranking $\beta^{\theta}$ loadings of the labor market tightness portfolios. Firms are assigned into deciles by $\beta^{\theta}$ at the end of every month $\tau$ and the value-weighted portfolios are held without rebalancing for 12 months beginning in month $\tau+2$. Excess returns of each portfolio are then regressed annually on the market and the labor market tightness factors, including two ? lags to account for effects of non-synchronous trading. Betas are averaged across the years to obtain average $\beta^{\theta}$ loadings for each portfolio. Panel A reports results for decile portfolios, and Panel B summarizes them for quintiles. The last column of each Panel shows the differences in post-ranking betas of the bottom and top groups. The sample period is $1954-2012$.

\section{A. Post-ranking betas of decile portfolios}

\begin{tabular}{cccccccccccc} 
& Low & 2 & 3 & 4 & 5 & 6 & 7 & 8 & 9 & High & Low - High \\
\hline$\beta^{\theta}$ & -0.07 & -0.13 & -0.13 & -0.01 & 0.00 & -0.06 & 0.13 & 0.04 & 0.15 & 0.18 & -0.25
\end{tabular}

\section{B. Post-ranking betas of quintile portfolios}

\begin{tabular}{rcccccr} 
& Low & 2 & 3 & 4 & High & Low - High \\
\hline$\beta^{\theta}$ & -0.10 & -0.06 & -0.01 & 0.06 & 0.10 & -0.20 \\
\hline
\end{tabular}


Table AIII

\section{Performance of Portfolios Sorted by Loadings on Market and Labor Market Tightness Factors}

This table reports average excess returns, in percent per month, for the quintile portfolios of stocks sorted on the basis of their loadings on the labor market tightness and market factors, as well as for the portfolio that is long the low quintile and short the high quintile. Firms are assigned into groups at the end of every month $\tau$ and the value-weighted portfolios are held without rebalancing for 12 months starting in month $\tau+2$. The bottom row and the last columns give $t$-statistics for the low-high portfolios. The sample period is 1954-2012.

\begin{tabular}{|c|c|c|c|c|c|c|c|}
\hline & Low $\beta^{M}$ & 2 & 3 & 4 & High $\beta^{M}$ & \multicolumn{2}{|c|}{ Low-High } \\
\hline \multicolumn{8}{|c|}{ A. Independent sorts } \\
\hline Low $\beta^{\theta}$ & 0.62 & 0.64 & 0.51 & 0.47 & 0.30 & 0.32 & [1.79] \\
\hline 2 & 0.64 & 0.54 & 0.54 & 0.39 & 0.23 & 0.41 & [2.53] \\
\hline 3 & 0.58 & 0.56 & 0.47 & 0.34 & 0.13 & 0.45 & {$[2.69]$} \\
\hline 4 & 0.61 & 0.51 & 0.42 & 0.25 & 0.20 & 0.41 & {$[2.43]$} \\
\hline High $\beta^{\theta}$ & 0.28 & 0.34 & 0.17 & 0.11 & -0.03 & 0.31 & {$[1.69]$} \\
\hline Low-High & 0.34 & 0.29 & 0.34 & 0.36 & 0.33 & & \\
\hline t-statistic & {$[2.27]$} & {$[2.31]$} & {$[2.61]$} & {$[2.73]$} & {$[2.60]$} & & \\
\hline \multicolumn{8}{|c|}{ B. Conditional sorts: first on $\beta^{\theta}$, then on $\beta^{M}$} \\
\hline Low $\beta^{\theta}$ & 0.63 & 0.60 & 0.44 & 0.39 & 0.30 & 0.33 & [1.78] \\
\hline 2 & 0.64 & 0.56 & 0.56 & 0.44 & 0.31 & 0.33 & {$[2.23]$} \\
\hline 3 & 0.59 & 0.59 & 0.47 & 0.38 & 0.21 & 0.39 & {$[2.66]$} \\
\hline 4 & 0.62 & 0.53 & 0.38 & 0.29 & 0.17 & 0.45 & {$[2.86]$} \\
\hline High $\beta^{\theta}$ & 0.31 & 0.31 & 0.04 & 0.04 & -0.04 & 0.35 & {$[1.80]$} \\
\hline Low-High & 0.32 & 0.29 & 0.40 & 0.35 & 0.34 & & \\
\hline t-statistic & {$[2.21]$} & {$[2.32]$} & {$[2.95]$} & {$[2.64]$} & {$[2.49]$} & & \\
\hline \multicolumn{8}{|c|}{ C. Conditional sorts: first on $\beta^{M}$, then $\beta^{\theta}$} \\
\hline & Low $\beta^{M}$ & 2 & 3 & 4 & High $\beta^{M}$ & \multicolumn{2}{|c|}{ Low-High } \\
\hline Low $\beta^{\theta}$ & 0.70 & 0.60 & 0.51 & 0.44 & 0.27 & 0.43 & {$[2.34]$} \\
\hline 2 & 0.63 & 0.53 & 0.55 & 0.41 & 0.19 & 0.44 & {$[2.61]$} \\
\hline 3 & 0.53 & 0.54 & 0.45 & 0.32 & 0.18 & 0.35 & [2.03] \\
\hline 4 & 0.62 & 0.53 & 0.44 & 0.22 & 0.14 & 0.48 & [2.79] \\
\hline High $\beta^{\theta}$ & 0.32 & 0.39 & 0.24 & 0.10 & -0.16 & 0.49 & [2.39] \\
\hline Low-High & 0.37 & 0.21 & 0.26 & 0.34 & 0.43 & & \\
\hline t-statistic & {$[2.70]$} & [1.91] & {$[2.24]$} & {$[2.53]$} & {$[2.95]$} & & \\
\hline
\end{tabular}




\section{Table AIV}

\section{Performance of Portfolios Sorted by Loadings on Components of Labor Market Tightness and Industrial Production}

This table reports four-factor alphas, in percent per month, for the ten portfolios of stocks sorted on the basis of $\beta^{V a c}, \beta^{U n e m p}, \beta^{L F P R}$, and $\beta^{I P}$, which are loadings from two-factor regressions of stock excess returns on market excess returns and log changes in either the vacancy index, the unemployment rate, the labor force participation rate, or industrial production, respectively. The bottom two rows show the alphas and the corresponding $t$-statistics for the portfolio that is long the low decile and short the high group. Firms are assigned into deciles at the end of every month $\tau$ on the basis of loadings computed using monthly data from $\tau-35$ to $\tau$, and the value-weighted portfolios are held without rebalancing for 12 months beginning in month $\tau+2$. The sample period is 1954-2012.

\begin{tabular}{lrrrr}
\hline & \multicolumn{4}{c}{ Four-factor alphas of portfolios sorted by } \\
\cline { 2 - 5 } Decile & $\beta^{\text {Vac }}$ & $\beta^{\text {Unemp }}$ & $\beta^{L F P R}$ & $\beta^{I P}$ \\
\hline Low & 0.02 & -0.22 & -0.05 & -0.07 \\
2 & 0.12 & -0.08 & -0.02 & 0.07 \\
3 & 0.11 & 0.01 & 0.02 & 0.04 \\
4 & 0.02 & 0.02 & 0.03 & 0.10 \\
5 & 0.02 & 0.11 & 0.03 & 0.05 \\
6 & 0.01 & 0.11 & 0.04 & 0.04 \\
7 & 0.10 & 0.04 & 0.04 & 0.02 \\
8 & 0.02 & 0.09 & 0.08 & -0.07 \\
9 & -0.05 & 0.13 & 0.10 & -0.07 \\
High & -0.22 & -0.01 & 0.08 & -0.07 \\
Low-High & 0.24 & -0.20 & -0.13 & -0.01 \\
t-statistic & {$[1.58]$} & {$[-1.33]$} & {$[-0.89]$} & {$[-0.06]$} \\
\hline
\end{tabular}




\section{Table AV}

\section{Fama-MacBeth Regressions of Annual Stock Returns}

This table reports the results of annual Fama-MacBeth regressions. Stock returns from July of year $T$ to June of year $T+1$ are regressed on $\beta^{M}$, market beta measured using three years of data ending in end of May of year $T ; \beta^{L F P R}, \beta^{U n e m p}, \beta^{V a c}$, and $\beta^{I P}$, loadings from twofactor regressions of stock excess returns on market excess returns and log changes in either labor force participation rate, unemployment rate, vacancy index, or industrial production, respectively, computed over the same period as $\beta^{M}$. Controls include log of market equity measured as of the end of June of year $T$; $\log$ of the ratio of book equity to market equity measured following Davis, Fama, and French (2000); 12-month stock return ending in June of year $T$; and new hiring, investment, and asset growth rates, defined as in Belo, Lin, and Bazdresch (2013). Reported are average coefficients and the corresponding Newey and West (1987) $t$-statistics. The sample period is 1954-2012. Details of definitions of the control variables are in Appendix A of the paper.

\begin{tabular}{|c|c|c|c|c|c|c|}
\hline Reg & $\beta^{M}$ & $\beta^{L F P R}$ & $\beta^{\text {Unemp }}$ & $\beta^{V a c}$ & $\beta^{I P}$ & Controls \\
\hline (1) & $\begin{array}{l}0.001 \\
{[0.04]}\end{array}$ & $\begin{array}{l}0.001 \\
{[1.19]}\end{array}$ & & & & $\mathrm{No}$ \\
\hline$(2)$ & $\begin{array}{r}0.000 \\
{[-0.01]}\end{array}$ & & $\begin{array}{l}0.011 \\
{[1.51]}\end{array}$ & & & No \\
\hline$(3)$ & $\begin{array}{l}0.001 \\
{[0.05]}\end{array}$ & & & $\begin{array}{l}-0.007 \\
{[-1.13]}\end{array}$ & & No \\
\hline (4) & $\begin{array}{l}0.001 \\
{[0.09]}\end{array}$ & & & & $\begin{array}{l}-0.001 \\
{[-0.43]}\end{array}$ & No \\
\hline (5) & $\begin{array}{r}0.000 \\
{[-0.00]}\end{array}$ & $\begin{array}{l}0.001 \\
{[1.08]}\end{array}$ & $\begin{array}{l}0.015 \\
{[1.51]}\end{array}$ & $\begin{array}{l}0.002 \\
{[0.35]}\end{array}$ & & $\mathrm{No}$ \\
\hline (6) & $\begin{array}{l}0.001 \\
{[0.05]}\end{array}$ & $\begin{array}{l}0.001 \\
{[1.35]}\end{array}$ & $\begin{array}{l}0.015 \\
{[1.15]}\end{array}$ & $\begin{array}{l}0.004 \\
{[0.48]}\end{array}$ & $\begin{array}{r}0.000 \\
{[-0.10]}\end{array}$ & No \\
\hline (7) & $\begin{array}{l}0.012 \\
{[0.86]}\end{array}$ & $\begin{array}{l}0.001 \\
{[1.54]}\end{array}$ & & & & Yes \\
\hline (8) & $\begin{array}{l}0.011 \\
{[0.81]}\end{array}$ & & $\begin{array}{l}0.021 \\
{[2.21]}\end{array}$ & & & Yes \\
\hline (9) & $\begin{array}{l}0.011 \\
{[0.77]}\end{array}$ & & & $\begin{array}{l}-0.024 \\
{[-3.36]}\end{array}$ & & Yes \\
\hline (10) & $\begin{array}{l}0.012 \\
{[0.86]}\end{array}$ & & & & $\begin{array}{l}-0.004 \\
{[-1.04]}\end{array}$ & Yes \\
\hline (11) & $\begin{array}{l}0.011 \\
{[0.79]}\end{array}$ & $\begin{array}{l}0.001 \\
{[1.21]}\end{array}$ & $\begin{array}{l}0.012 \\
{[1.14]}\end{array}$ & $\begin{array}{l}-0.017 \\
{[-1.25]}\end{array}$ & & Yes \\
\hline (12) & $\begin{array}{l}0.012 \\
{[0.86]}\end{array}$ & $\begin{array}{l}0.001 \\
{[1.34]}\end{array}$ & $\begin{array}{l}0.012 \\
{[0.96]}\end{array}$ & $\begin{array}{l}-0.015 \\
{[-1.06]}\end{array}$ & $\begin{array}{r}0.000 \\
{[-0.11]}\end{array}$ & Yes \\
\hline
\end{tabular}




\section{Table AVI \\ Loadings of 48 Industries on the Labor Market Tightness Factor}

This table reports in the first three numerical columns unconditional loadings, average conditional loadings, and standard deviation of conditional loadings $\beta^{\theta}$ on the labor market tightness factor for industry portfolios. Loadings are computed as in regression (3). Conditional betas are based on rolling three-year regressions. The last three columns show the fraction of months each industry was assigned to low and high $\beta^{\theta}$ quintiles and the difference between the two fractions. Definitions of 48 industries are from Ken French's data library. The sample period is 1954-2012 for all industries except Candy \& Soda (1963-2012), Defense

(1963-2012), Fabricated Products (1963-2012), Healthcare (1969-2012), and Precious Metals (1963-2012). 


\begin{tabular}{|c|c|c|c|c|c|c|}
\hline \multirow[b]{2}{*}{ Industry } & \multirow[b]{2}{*}{$\begin{array}{r}\text { Uncond } \\
\beta^{\theta} \\
\end{array}$} & \multirow[b]{2}{*}{$\begin{array}{l}\text { Average } \\
\text { cond } \beta^{\theta}\end{array}$} & \multirow[b]{2}{*}{$\begin{array}{l}\text { Standard } \\
\text { dev of } \beta^{\theta}\end{array}$} & \multicolumn{2}{|c|}{ Fraction of months in } & \multirow[b]{2}{*}{$\begin{array}{l}\text { Low-High } \\
\text { difference }\end{array}$} \\
\hline & & & & $\begin{array}{l}\text { low } \beta^{\theta} \\
\text { quintile }\end{array}$ & $\begin{array}{l}\text { high } \beta^{\theta} \\
\text { quintile }\end{array}$ & \\
\hline Precious Metals & -0.143 & -0.097 & 0.612 & 0.595 & 0.211 & 0.384 \\
\hline Tobacco Products & -0.112 & -0.086 & 0.211 & 0.416 & 0.152 & 0.263 \\
\hline Food Products & -0.050 & -0.022 & 0.114 & 0.213 & 0.094 & 0.119 \\
\hline Beer \& Liquor & -0.050 & -0.063 & 0.162 & 0.337 & 0.060 & 0.277 \\
\hline Coal & -0.049 & -0.019 & 0.272 & 0.355 & 0.313 & 0.042 \\
\hline Utilities & -0.042 & -0.047 & 0.106 & 0.271 & 0.047 & 0.224 \\
\hline Banking & -0.039 & -0.030 & 0.151 & 0.287 & 0.094 & 0.193 \\
\hline Business Services & -0.037 & -0.023 & 0.113 & 0.075 & 0.079 & -0.004 \\
\hline Computers & -0.029 & -0.016 & 0.175 & 0.220 & 0.235 & -0.015 \\
\hline Candy \& Soda & -0.029 & -0.025 & 0.187 & 0.267 & 0.239 & 0.028 \\
\hline Retail & -0.026 & 0.005 & 0.106 & 0.069 & 0.157 & -0.087 \\
\hline Electronic Equipment & -0.026 & -0.019 & 0.133 & 0.166 & 0.152 & 0.014 \\
\hline Medical Equipment & -0.024 & -0.018 & 0.155 & 0.278 & 0.136 & 0.143 \\
\hline Communication & -0.015 & -0.031 & 0.103 & 0.123 & 0.118 & 0.006 \\
\hline Shipping Containers & -0.015 & -0.018 & 0.112 & 0.137 & 0.123 & 0.014 \\
\hline Almost Nothing & -0.006 & -0.006 & 0.220 & 0.208 & 0.186 & 0.022 \\
\hline Agriculture & -0.004 & 0.002 & 0.206 & 0.319 & 0.201 & 0.118 \\
\hline Recreation & -0.002 & 0.028 & 0.247 & 0.188 & 0.295 & -0.107 \\
\hline Insurance & -0.001 & 0.000 & 0.133 & 0.204 & 0.114 & 0.090 \\
\hline Healthcare & -0.001 & 0.040 & 0.273 & 0.297 & 0.291 & 0.006 \\
\hline Entertainment & 0.000 & 0.010 & 0.165 & 0.260 & 0.209 & 0.051 \\
\hline Construction & 0.002 & 0.008 & 0.173 & 0.274 & 0.213 & 0.061 \\
\hline Pharmaceutical Products & 0.003 & 0.004 & 0.128 & 0.152 & 0.169 & -0.017 \\
\hline Petroleum and Natural Gas & 0.003 & 0.001 & 0.136 & 0.220 & 0.144 & 0.076 \\
\hline Consumer Goods & 0.003 & 0.006 & 0.093 & 0.032 & 0.079 & -0.047 \\
\hline Apparel & 0.005 & 0.038 & 0.142 & 0.078 & 0.190 & -0.112 \\
\hline Steel Works Etc & 0.006 & 0.005 & 0.149 & 0.209 & 0.166 & 0.043 \\
\hline Restaurants, Hotels, Motels & 0.006 & 0.013 & 0.149 & 0.159 & 0.233 & -0.073 \\
\hline Chemicals & 0.007 & -0.008 & 0.083 & 0.073 & 0.144 & -0.071 \\
\hline Construction Materials & 0.009 & 0.021 & 0.119 & 0.065 & 0.105 & -0.040 \\
\hline Printing and Publishing & 0.010 & 0.007 & 0.152 & 0.161 & 0.220 & -0.060 \\
\hline Shipbuilding, Railroad Equipment & 0.012 & 0.021 & 0.204 & 0.262 & 0.244 & 0.018 \\
\hline Personal Services & 0.013 & 0.012 & 0.178 & 0.202 & 0.202 & 0.000 \\
\hline Transportation & 0.013 & 0.006 & 0.120 & 0.129 & 0.112 & 0.017 \\
\hline Trading & 0.014 & 0.017 & 0.113 & 0.066 & 0.158 & -0.091 \\
\hline Fabricated Products & 0.015 & 0.011 & 0.240 & 0.274 & 0.277 & -0.003 \\
\hline Electrical Equipment & 0.016 & 0.020 & 0.093 & 0.042 & 0.194 & -0.152 \\
\hline Defense & 0.017 & 0.019 & 0.212 & 0.284 & 0.274 & 0.010 \\
\hline Aircraft & 0.021 & 0.024 & 0.128 & 0.224 & 0.195 & 0.029 \\
\hline Non-Metallic and Industrial Metal Mining & 0.022 & 0.042 & 0.202 & 0.267 & 0.258 & 0.010 \\
\hline Measuring and Control Equipment & 0.022 & 0.036 & 0.121 & 0.141 & 0.230 & -0.089 \\
\hline Machinery & 0.023 & 0.027 & 0.103 & 0.043 & 0.132 & -0.089 \\
\hline Rubber and Plastic Products & 0.028 & 0.031 & 0.125 & 0.121 & 0.216 & -0.096 \\
\hline Business Supplies & 0.030 & 0.033 & 0.119 & 0.116 & 0.230 & -0.114 \\
\hline Real Estate & 0.031 & 0.071 & 0.195 & 0.127 & 0.355 & -0.227 \\
\hline Wholesale & 0.033 & 0.043 & 0.114 & 0.026 & 0.134 & -0.108 \\
\hline Textiles & 0.044 & 0.056 & 0.140 & 0.073 & 0.284 & -0.211 \\
\hline Automobiles and Trucks & 0.061 & 0.042 & 0.117 & 0.069 & 0.425 & -0.356 \\
\hline
\end{tabular}

